\title{
Composite Materials Based on Iron Oxide Nanoparticles and Polyurethane for Improving the Quality of MRI
}

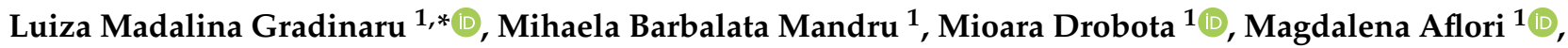 \\ Maria Butnaru 1,2, Maria Spiridon ${ }^{1}$, Florica Doroftei ${ }^{1}$, Mihaela Aradoaei ${ }^{3,4}$, Romeo Cristian Ciobanu ${ }^{3,4}$ \\ and Stelian Vlad ${ }^{1, *(1)}$
}

1 "Petru Poni" Institute of Macromolecular Chemistry, Gr. Ghica Voda Alley, 41A, 700487 Iasi, Romania; mihaelamandru84@gmail.com (M.B.M.); miamiara@icmpp.ro (M.D.); maflori@icmpp.ro (M.A.); mariabutnaru@yahoo.com (M.B.); dana_spiridon_is@yahoo.com (M.S.); florica.doroftei@icmpp.ro (F.D.)

2 Department of Biomedical Sciences, "Grigore T. Popa" University of Medicine and Pharmacy, Kogalniceanu Street, 9-13, 700115 Iasi, Romania

3 Electrical Engineering Faculty, "Gheorghe Asachi" Technical University of Iasi, Dimitrie Mangeron Bd., 67, 700050 Iasi, Romania; mihaela.aradoaei@academic.tuiasi.ro (M.A.); rciobanu@yahoo.com (R.C.C.)

4 SC All Green SRL, I. Bacalu Street, 5, 700029 Iasi, Romania

* Correspondence: gradinaru.luiza@icmpp.ro (L.M.G.); vladus@icmpp.ro (S.V.)

Citation: Gradinaru, L.M.; Barbalata Mandru, M.; Drobota, M.; Aflori, M.; Butnaru, M.; Spiridon, M.; Doroftei,

F.; Aradoaei, M.; Ciobanu, R.C.; Vlad,

S. Composite Materials Based on Iron

Oxide Nanoparticles and

Polyurethane for Improving the Quality of MRI. Polymers 2021, 13 , 4316. https://doi.org/10.3390/ polym13244316

Academic Editor: Javier González-Benito

Received: 4 November 2021

Accepted: 3 December 2021

Published: 9 December 2021

Publisher's Note: MDPI stays neutral with regard to jurisdictional claims in published maps and institutional affiliations.

Copyright: (C) 2021 by the authors Licensee MDPI, Basel, Switzerland. This article is an open access article distributed under the terms and conditions of the Creative Commons Attribution (CC BY) license (https:// creativecommons.org/licenses/by/ $4.0 /)$
Abstract: Polyether urethane (PU)-based magnetic composite materials, containing different types and concentrations of iron oxide nanostructures $\left(\mathrm{Fe}_{2} \mathrm{O}_{3}\right.$ and $\left.\mathrm{Fe}_{3} \mathrm{O}_{4}\right)$, were prepared and investigated as a novel composite platform that could be explored in different applications, especially for the improvement of the image quality of MRI investigations. Firstly, the PU structure was synthetized by means of a polyaddition reaction and then hematite $\left(\mathrm{Fe}_{2} \mathrm{O}_{3}\right)$ and magnetite $\left(\mathrm{Fe}_{3} \mathrm{O}_{4}\right)$ nanoparticles were added to the PU matrices to prepare magnetic nanocomposites. The type and amount of iron oxide nanoparticles influenced its structural, morphological, mechanical, dielectric, and magnetic properties. Thus, the morphology and wettability of the PU nanocomposites surfaces presented different behaviours depending on the amount of the iron oxide nanoparticles embedded in the matrices. Mechanical, dielectric, and magnetic properties were enhanced in the composites' samples when compared with pristine PU matrix. In addition, the investigation of in vitro cytocompatibility of prepared PU nanocomposites showed that these samples are good candidates for biomedical applications, with cell viability levels in the range of $80-90 \%$. Considering all the investigations, we can conclude that the addition of magnetic particles introduced additional properties to the composite, which could significantly expand the functionality of the materials developed in this work.

Keywords: polyurethane; iron oxide nanoparticles; composites; MRI

\section{Introduction}

In recent years, the molecular imaging technique has attracted much interest due to its non-invasive procedure, which consists of a combination of in vivo imaging and molecular biology, aiming at the identification of living biological process at the cellular and molecular level [1]. Thus, molecular imaging permits quantitative characterization that allows the non-invasive monitoring and early diagnosis of diseases, and is mainly used for cell tracking, angiogenesis, apoptosis, and in vivo tissue gene imaging [2].

Magnetic resonance imaging (MRI) is one of the major imaging methods because of the combination of several advantages: convenient non-invasive application, high spatial resolution, and tomographic capability. MRI shows its great supremacy in the practical application of clinical diagnosis, as well as in biomedical research [3], and is mainly used to obtain high quality images of the inside of the human body. MRI has the advantages of relatively high resolution $(25 \div 100 \mu \mathrm{m})$ and superior tissue penetration depth, while its sensitivity requires substantial improvement compared with the direct optical imaging 
technique [4]. Moreover, this technique is based on the principles of nuclear magnetic resonance (NMR), a spectroscopic technique used by researchers to obtain chemical and physical information about molecules [2]. However, as with any other imaging modality, MRI is vulnerable to artifacts that arise for different reasons, such as data acquisition, image reconstruction processes, scanning parameters, etc. Various correction methods have been developed to mitigate the corruptive effects of artifacts and to improve image diagnostic quality, most of them regarding the procedure, equipment, or postprocessing algorithms [5]. Another drawback of this method consists in the use of contrast agents that could provoke a series of hemodynamic changes, anaphylactic reactions, or side effects due to their oral or intravascular administration $[3,4,6]$.

Since inorganic nanoparticles commonly have remarkably high thermal and mechanical properties, a wide range of them have been used as fillers in different types of polymer matrices to improve their properties [6-9]. Their nanoscale dimensions lead to high surface energy, which allows efficient mixing with a polymer matrix at the molecular level. Among inorganic nanoparticles, magnetic nanoparticles have unique multifunctional properties and numerous applications $[6,10]$.

Iron oxide nanoparticles, which belong to the ferromagnetic class of magnetic materials, have attracted incredible interest since they are biocompatible and show exceptional electric, thermal, mechanical, and magnetic properties and, thus, are utilized for many different biomedical and bioengineering applications $[6,11,12]$. The most common iron oxide forms available are hematite $\left(\alpha-\mathrm{Fe}_{2} \mathrm{O}_{3}\right)$, maghemite $\left(\gamma-\mathrm{Fe}_{2} \mathrm{O}_{3}\right)$ and magnetite $\left(\mathrm{Fe}_{3} \mathrm{O}_{4}\right)$, which are used in different technological, industrial, and biomedical applications [13].

Incorporating different types of iron oxide nanoparticles into organic polymers to afford nanocomposites is of great interest because of the versatile properties of this class of organic-inorganic composite. Moreover, the preparation of composites with magnetic properties allows the production of some functional complex components such as electromagnetic screening devices and other electrical systems [14].

Among the different polymer matrices that can be used to embed nanoparticles, polyurethanes (PU) are of particular interest because of their wide range of applications in different fields, including as textiles, adhesives, and coatings in the construction, automotive, and especially biomedical engineering fields [15-19]. PUs are multi-segmented polymers, prepared from the reaction of polyols, diisocyanates, and diols. Therefore, PUs have alternating hard and soft blocks that lead to microphase separation under appropriate conditions, possessing elastomeric character and extra strength. This polymer type is capable of easily changing its properties by varying the chemical composition or adding filler reinforcement agents [20]. A significant effort has been made to develop new strategies to obtain different magnetic PU materials that can be used as adhesives [21], as encapsulating materials for flexible organic photovoltaic cells [22], as coatings [23], in decontamination/filtration [24-26], in the preparation of microwave-absorbing materials [27], and especially in biomedical applications $[20,28,29]$. The incorporation of nanoparticles into the PU matrix has the following advantages: a structural support and a functionalization of the matrix is provided by increasing the dispersibility of the nanoparticles and, secondly, their incorporation confers magnetic properties and antibacterial activity to the polymer [12]. Moreover, the presence of iron oxide nanoparticles into polyurethane matrix can change the molecular structures through interaction with polar groups of the polyurethane via different inter- and intramolecular interactions. They act as a cross-linking agent leading to ordered and reinforced nanocomposite structures [20,30]. Studies confirmed that PU embedded with iron oxide nanoparticles were utilized to improve some characteristics of PUs, such as electric [15], magnetic [10], thermal [13], mechanical [31-33], and shape memory [31] properties. Properties such as crystallinity, mechanical strength, surface roughness, hydrophilicity, and eventually cell fates can be changed through the incorporation of such nanoparticles to the PU matrix [20]. Moreover, by combining the properties of the polyurethane structures such as high elasticity, good conductibility, stability, and 
biocompatibility, with those of iron oxide nanoparticles, especially magnetization, novel composites could be developed to improve the image quality in MRI investigations.

The aim of the present study was to synthesize and characterize novel magnetic nanocomposites based on the use of poly(ether-urethane) as the matrix and two types of iron oxide nanoparticles $\left(\mathrm{Fe}_{2} \mathrm{O}_{3}\right.$ and $\left.\mathrm{Fe}_{3} \mathrm{O}_{4}\right)$ as the nano-sized fillers. This is the first step in the development of such materials that could be explored as custom-tailored composites for the preparation of suitable devices to improve the image quality in MRI investigations, when, for various reasons, defects in the clarity of images appear. This device should act as an image amplifier that should be placed at the points where the MRI image does not cover areas of vital interest-for example, in the case of brain tumours. Therefore, pristine and nanocomposite PU films were prepared via solution casting by embedding different weight percentages $(0.1 ; 0.5 ; 1 \%)$ of each $\mathrm{Fe}_{2} \mathrm{O}_{3}$ and $\mathrm{Fe}_{3} \mathrm{O}_{4}$ nanoparticle into PU matrices (30 wt.\% in DMF) through blending. Then, the influence of the nanoparticles amounts on the structural, morphological, mechanical, dielectric, and magnetic properties was investigated. In addition, in vitro cytocompatibility was also verified by MTT assay and cell.morphology.

\section{Materials and Methods}

\subsection{Materials}

Poly(tetrahydrofuran) (Terathane polyether glycol) (PTHF) with $\mathrm{M}_{\mathrm{n}} 2000 \mathrm{~g} / \mathrm{mol}, 1$,4butanediol (BD), poly (dimethylsiloxane) bis(hydroxyalkyl) terminated (PDMS) with $\mathrm{M}_{\mathrm{n}}$ $5600 \mathrm{~g} / \mathrm{mol}$ and N,N-dimethylformamide (DMF) were purchased from Sigma-Aldrich (Steinheim, Germany). 4,4'-diphenylmethane diisocyanate (MDI) was obtained from Fluka (Steinheim, Germany) and was fresh distilled prior to use. Iron (III) oxide nano powder $\left(\mathrm{Fe}_{2} \mathrm{O}_{3}\right)$ of $<50 \mathrm{~nm}$ particle size and Iron (II, III) oxide nano powder $\left(\mathrm{Fe}_{3} \mathrm{O}_{4}\right)$ of $50-100 \mathrm{~nm}$ particle size (SEM) were used as the magnetic particles throughout the investigation and were also purchased from Sigma-Aldrich (Steinheim, Germany).

For determination of contact angle values, four test liquids with different surface tensions [34,35] were selected: Milli-Q purified water (Millipore, $\geq 18.2 \mathrm{M} \Omega \mathrm{cm}$ ), ethylene glycol (anhydrous $99.8 \%$, Sigma-Aldrich, Steinheim, Germany), formamide (99\%, SigmaAldrich, Steinheim, Germany), and methylene iodide (99\%, Sigma-Aldrich, Steinheim, Germany). All other chemicals were used as received without further purification.

\subsection{Preparation Methods}

\subsubsection{Synthesis of Pristine PU}

PU was synthetized using a polymerization solution method based on a previously reported procedure [36,37]. Briefly, in a four-necked glass reaction vessel equipped with a stirrer, a dropping funnel, and an $\mathrm{N}_{2}$ inlet and outlet, one equivalent quantity of PTHF was dehydrated under vacuum $(1-3 \mathrm{mmHg})$ and temperature $\left(100^{\circ} \mathrm{C}\right)$ for $4 \mathrm{~h}$. Then, the reaction vessel was brought to atmospheric pressure under nitrogen and the temperature was decreased until $80^{\circ} \mathrm{C}$ was reached. Then, two equivalent quantities of MDI were added and stirred at $80^{\circ} \mathrm{C}$ for $2 \mathrm{~h}$. After two dilution steps, the prepolymer was extended with the required amount of $\mathrm{BD}$ and PDMS solution in DMF. The molar ratio of the reactants PTHF:MDI:BD/PDMS was 1:3:2 (Scheme 1). 


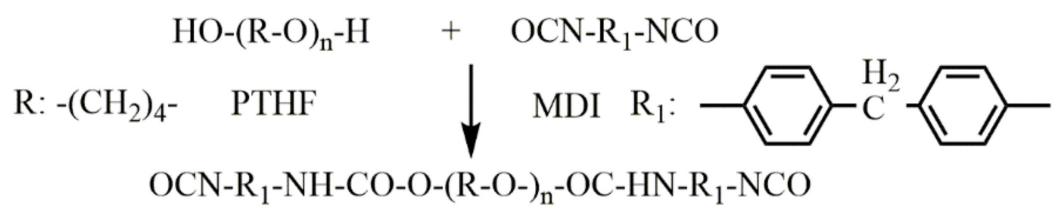

Polyurethane prepolymer

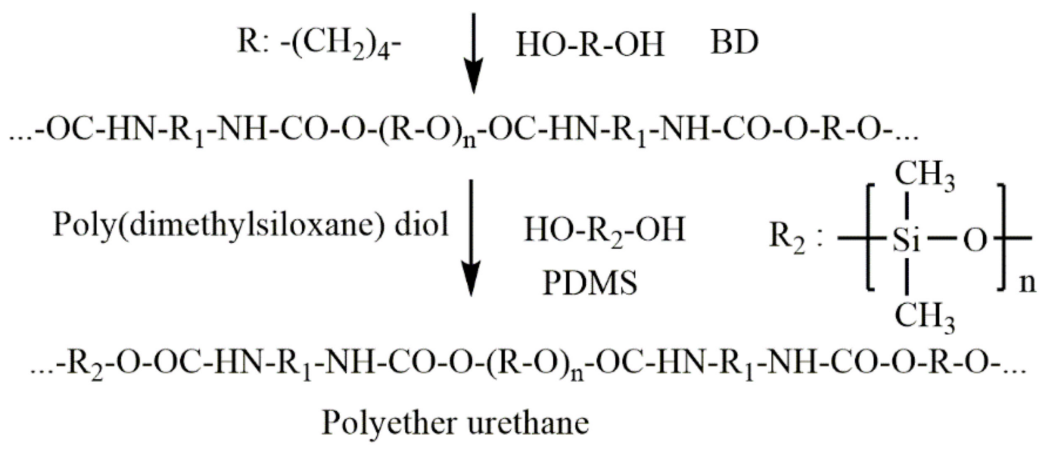

Scheme 1. The schematic illustration of the synthesis route of pristine PU.

\subsubsection{Preparation of $\mathrm{Fe}_{2} \mathrm{O}_{3}$ and $\mathrm{Fe}_{3} \mathrm{O}_{4}$ PU Nanocomposites}

Six different $\mathrm{Fe}_{2} \mathrm{O}_{3}$ and $\mathrm{Fe}_{3} \mathrm{O}_{4}$ PU nanocomposites were prepared by embedding different weight percentages $\left(0.1 ; 0.5 ; 1 \%\right.$ ) of each $\mathrm{Fe}_{2} \mathrm{O}_{3}$ and $\mathrm{Fe}_{3} \mathrm{O}_{4}$ nanoparticle into PU matrices ( $30 \mathrm{wt} . \%$ in DMF) through blending. Thereby, the dispersions were stirred vigorously for $2 \mathrm{~h}$ and then were ultrasonicated for $6 \mathrm{~h}$ to obtain stable and homogeneous suspensions. Pristine and nanocomposite PU films (approximately $0.2 \mathrm{~mm}$ in thickness) were prepared by solvent casting of the final suspension on a glass plate followed by drying at room temperature and low pressure $(1-2 \mathrm{mmHg}$ ) for $24 \mathrm{~h}$. Sample code designations and formulations of pure PU and nanocomposites are given in Table 1.

Table 1. Sample code designations and formulations of pure PU and nanocomposites.

\begin{tabular}{cccc}
\hline Sample Code & $\begin{array}{c}\text { Molar Ratio } \\
\text { (PTHF:MDI:BG/PDMS) }\end{array}$ & Nanoparticle Type & $\begin{array}{c}\text { Nanoparticle } \\
\text { Content } \\
\text { (wt } \%)\end{array}$ \\
\hline PU & $1: 3: 2$ & $\mathrm{None}$ & 0 \\
P1-0.1 & $1: 3: 2$ & $\mathrm{Fe}_{2} \mathrm{O}_{3}$ & 0.1 \\
P1-0.5 & $1: 3: 2$ & $\mathrm{Fe}_{2} \mathrm{O}_{3}$ & 0.5 \\
P1-1 & $1: 3: 2$ & $\mathrm{Fe}_{2} \mathrm{O}_{3}$ & 1 \\
P2-0.1 & $1: 3: 2$ & $\mathrm{Fe}_{3} \mathrm{O}_{4}$ & 0.1 \\
P2-0.5 & $1: 3: 2$ & $\mathrm{Fe}_{3} \mathrm{O}_{4}$ & 0.5 \\
P2-1 & $1: 3: 2$ & $\mathrm{Fe}_{3} \mathrm{O}_{4}$ & 1 \\
\hline
\end{tabular}

${ }^{*}$ Molar ratio of polyol:diisocyanate:chain extender.

\subsection{Characterization Technique}

2.3.1. Fourier Transform Infrared-Attenuated Total Reflectance (FTIR-ATR) Spectroscopy

The infrared spectra of pristine and PU nanocomposites were recorded using a Bruker LUMOS-FT-IR Microscope (Bruker Optik GmbH, Ettlingen, Germany) with an ATR reflection module (Attenuated Total Reflection) and a diamond crystal, at a single reflection angle of $45^{\circ}$ equipped with OPUS 8 software for spectral processing. The surfaces were scanned in the $500-4000 \mathrm{~cm}^{-1}$ range with a resolution of $2 \mathrm{~cm}^{-1}$, with averaging over 64 scans. The spectra were recorded at a constant temperature of $25^{\circ} \mathrm{C}$.

\subsubsection{Mechanical Analysis}

Tensile tests of the dumbbell-shaped pristine and nanocomposite PU strips $(50 \mathrm{~mm} \times 8.5 \mathrm{~mm} \times 4 \mathrm{~mm})$ were carried out at room temperature $\left(20-22^{\circ} \mathrm{C}\right)$, using 
a universal testing machine (Instron, Norwood, MA, USA), operated with a speed of $30 \mathrm{~mm} / \mathrm{min}$. Three replicates were used for each sample to obtain the averaged values and standard deviation. Elongation at break and tensile strength values were directly determined from the stress-strain curves. The Young's modulus was evaluated from the slope of the stress-strain curve in the linear region at low deformation.

\subsubsection{Scanning Electron Microscopy (SEM) Analysis}

The surface morphology, dispersion of the nanoparticles in PU nanocomposites, and elemental composition were evaluated with a Verios G4 UC scanning electron microscope (Thermo Scientific, Waltham, MA, USA) equipped with an energy-dispersive $x$-ray spectroscopy analyser (Octane Elect Super SDD detector(AMETEK, Tokyo, Japan). Before image acquisition, the samples were coated with $10 \mathrm{~nm}$ platinum using a Leica EM ACE 200 Sputter Coater (Leica Microsystems, Vienna, Austria) to provide electrical conductivity and to prevent charge build up during exposure to the electron beam. SEM investigations were performed in High Vacuum mode using a secondary electron detector (Everhart-Thornley detector, ETD) at an accelerating voltage of $5 \mathrm{kV}$. The pore diameters were determined from SEM images using ImageJ software. From each image, at least 50 different pores were randomly selected, and their diameters were measured to generate an average.

\subsubsection{Surface Topography}

A stylus profiler Tencor Alpha-Step D-500 was used for studying the surface topography of the samples with the amplitude parameters (KLA Tencor Corporation, Milpitas, CA, USA), such as the average roughness ( $\mathrm{Ra})$ and the root mean square roughness (Rq). The measured heights of the steps had an accuracy ranging between $10 \AA$ and $1.2 \mathrm{~mm}$. The device measured the roughness parameters with a recording speed of $0.10 \mathrm{~mm} / \mathrm{s}$ and a filtration interval of $0.060 \mathrm{~mm}$. The average roughness $(\mathrm{Ra})$ was calculated as representative roughness information. The reported Ra values were the average of 5 readings corresponding to different places and different directions.

\subsubsection{Contact Angle Determination and Surface Wettability Study}

Static contact angle (SCA) measurements were also implemented via the sessile drop method using a CAM 101 Optical Contact Angle Instrument (KSV Instruments, Helsinki, Finland) equipped with a special optical system (charge-couple device-CCD) connected to a computer. SCA measurements of distilled and deionized water (W), ethylene glycol (EG), formamide (FA), and di-iodomethane (dIM) were measured to examine the wettability of the PU surface samples with or without iron oxide nanoparticles. Five measurements conducted on different parts of the samples were averaged. Measurements were performed on dried surfaces at room temperature.

Surface tension parameters of the samples were estimated adopting the method developed by Owens, Wendt, Rabel, and Kaelble [35], based on the SCA values, as shown in the following equation:

$$
\frac{1+\cos \theta}{2} \cdot \frac{\gamma_{l v}}{\sqrt{\gamma_{l v}^{d}}}=\sqrt{\gamma_{s v}^{p}} \cdot \sqrt{\frac{\gamma_{l v}^{p}}{\gamma_{l v}^{d}}}+\sqrt{\gamma_{s v}^{d}} ; \gamma_{s v}=\gamma_{s v}^{d}+\gamma_{s v}^{p}
$$

where $\theta$ is the SCA determined with the test liquids, the subscripts " $l v$ " and " $s v$ " denote the interfacial tension between liquid-vapour and surface-vapour, respectively, while the superscripts " $p$ " and " $d$ " denote the polar and disperse components, respectively, of the total surface tension $\gamma_{s v}$.

The interfacial solid-liquid tension $\left(\gamma_{s l}\right)$ is calculated based on the following equation:

$$
\gamma_{s l}=\gamma_{s v}+\gamma_{l v}-2\left(\sqrt{\gamma_{s v}^{p} \gamma_{l v}^{p}}+\sqrt{\gamma_{s v}^{d} \gamma_{l v}^{d}}\right)
$$


The critical surface tension $\left(\gamma_{c}\right)$ was estimated using Zisman's method [35] and it was derived from a plot of $\cos \theta$ versus the surface tension of various test liquids. The linear regression extrapolated value of this tension at $\cos \theta=1$ gave $\gamma_{c}$ and represented the maximum surface tension of a liquid that could completely wet the substrate.

The work of adhesion $\left(W_{a}\right)$ was calculated using Young-Dupre equation $[35,38]$ :

$$
W_{a}=\gamma_{l v}(1+\cos \theta)
$$

The spreading coefficient $(S)$ can also be calculated as the difference between the adhesion $\left(W_{a}\right)$ and cohesion $\left(W_{c}\right)$ work [39].

$$
S=W_{a}-W_{c}
$$

where $W_{c}=2 \gamma_{l v}$.

\subsubsection{Determination of Dynamic Vapours' Sorption and Diffusion Coefficients}

The dynamic vapours' sorption (DVS) capacity of the nanocomposite samples was measured in a dynamic regime using an automated gravimetric analyser IGAsorp apparatus (Hiden Analytical, Warrington, UK). The IGAsorp is a standard sorption apparatus, equipped with a sensitive microbalance (resolution $1 \mathrm{mg}$ and capacity $200 \mathrm{mg}$ ), which continuously registers the weight of the sample together with the temperature and relative humidity. Based on the experimental isotherm data of the sorption-desorption experiment at $25{ }^{\circ} \mathrm{C}$, the diffusion coefficients could be determined using Fick's first and second laws. Crank [40] deduced that the diffusion coefficient for short time periods $\left(M_{t} / M_{\infty}<0.5\right)$ is described by Equation (5):

$$
\frac{M_{t}}{M_{\infty}}=\frac{4}{l} \sqrt{\frac{D_{1} \cdot t}{\pi}}
$$

where $M_{t}(\mathrm{~g})$ is the mass of sorbed water vapour at time $t(\mathrm{~s}), M_{\infty}(\mathrm{g})$ is the mass sorbed at $t=\infty, 1(\mathrm{~cm})$ is the sample thickness and $D\left(\mathrm{~cm}^{2} / \mathrm{s}\right)$ is the Fickian diffusion coefficient. The Fickian diffusion coefficient of the water vapour was determined from the initial slope of the $\left(M_{t} / M_{\infty}\right)^{2}$ versus $t^{1 / 2}$ plot (extracted from kinetic sorption experiments). At longer time $\left(M_{t} / M_{\infty}>0.5\right)$, the Fickian diffusion coefficient could be deduced from Equation (6):

$$
\frac{M_{t}}{M_{\infty}}=1-\frac{8}{\pi^{2}} e^{\frac{-D_{2} \pi^{2} t}{l^{2}}}
$$

\subsubsection{Dielectric Analysis}

The equipment for determining the dielectric measurements consisted of the following: anAlpha-N Frequency Analyzer from Novocontrol GmBH, Montabaur, Germany; a RhodeSchwartz NVR Network Analyzer (Milpitas, CA, USA), which worked in the frequency range of $20 \mathrm{kHz} \div 8 \mathrm{GHz}$, impedance $0.1 \Omega \ldots 10 \mathrm{k} \Omega$, tan $(\delta)$ accuracy $>3 \times 10^{-2}$; a QUATRO-Power temperature control unit (Novocontrol GmBH, Montabaur, Germany), with an accuracy of $0.01{ }^{\circ} \mathrm{C}$ and stabilization with an accuracy of $0.1{ }^{\circ} \mathrm{C}$; and the WinDETA/WinFIT software packages for measurement, calibration, and analysis. The dielectric characteristics as a function of frequency were studied at the temperature of $25^{\circ} \mathrm{C}$.

\subsubsection{Magnetic Determination}

The assessment of the magnetic properties of the samples was performed at ambient temperature, using an MPMS3 (7 T) SQUID vibrating-sample magnetometer (VSM) operated in DC mode (Lake Shore Cryotronics, Woburn, MA, USA. The magnetic field was swept from $-30,000$ to 30,000 Oe with a stepwise progression of 50 Oe. 


\subsection{In Vitro Evaluation of Biocompatibility-MTT Assay}

Initial preliminary cytotoxicity tests were performed using a mammalian MCF 7 epithelial cell line (purchased from European Collection of Cell Cultures (ECACC)) at a concentration of $20 \times 10^{4}$ cells/well and a yellow 3-(4,5-dimethylthiazol-2-yl)-2,5-diphenyl tetrazolium bromide (MTT) assay. This is a quantitative colorimetric method, based on the capacity of the cell to reduce the yellow tetrazolium salts to intense purple formazan by means of an intracellular reduction system mostly located in the mitochondria. The MTT assay is widely used for the assessment of cell viability and proliferation studies [41]. Briefly, after incubation of PU materials with cells for 48 and $72 \mathrm{~h}$, the MTT solution $(0.25 \mathrm{mg} / \mathrm{mL})$ was added and incubated with for $3 \mathrm{~h}$ in the dark, at $37^{\circ} \mathrm{C}$. After incubation, formazan crystals were solubilized with isopropanol and quantified by spectrophotometry at $570 \mathrm{~nm}$. The amount of formazan was correlated with number of viable cells. The cell viability was normalized to that of epithelial cells cultured in the media with negative control (without material). The experiments were performed in triplicate and the results are presented as mean \pm standard deviation (SD).

The morphology of the cells was also examined, after $72 \mathrm{~h}$ of direct contact of the samples with cells, by fluorescence and phase-contrast microscopy. The cells were fixed with an aqueous solution of formaldehyde and stained with 2-(4-amidinophenyl)- $1 \mathrm{H}$ indole-6-carboxamidine (DAPI) for nuclei observation. The blue fluorescence of the cell nuclei was detected using a 358/461 nm excitation/emission filter with a Leica DMIL inverted microscope (Leica, Wetzlar, Germany).

\subsection{Statistical Analysis}

For tests that produced numerical values, the test results were expressed as mean \pm standard deviation (SD). For results obtained from different groups or different time points, statistical analysis was performed using one-way analysis of variance (ANOVA). The $p$ value $<0.05$ was considered to be statistically significant.

\section{Results and Discussion}

\subsection{FTIR-ATR Analysis}

IR spectroscopy is an important and popular investigation technique that provides very useful information about the chemical composition and molecular structure, and also about the structure-properties relationship. The pure and $\mathrm{PU}$ nanocomposite samples were examined by FTIR-ATR analysis and, in Figure 1, the IR spectra of pure $\mathrm{Fe}_{2} \mathrm{O}_{3}$ and $\mathrm{Fe}_{3} \mathrm{O}_{4}$ nanoparticles, and pristine PU and PU nanocomposites are presented.
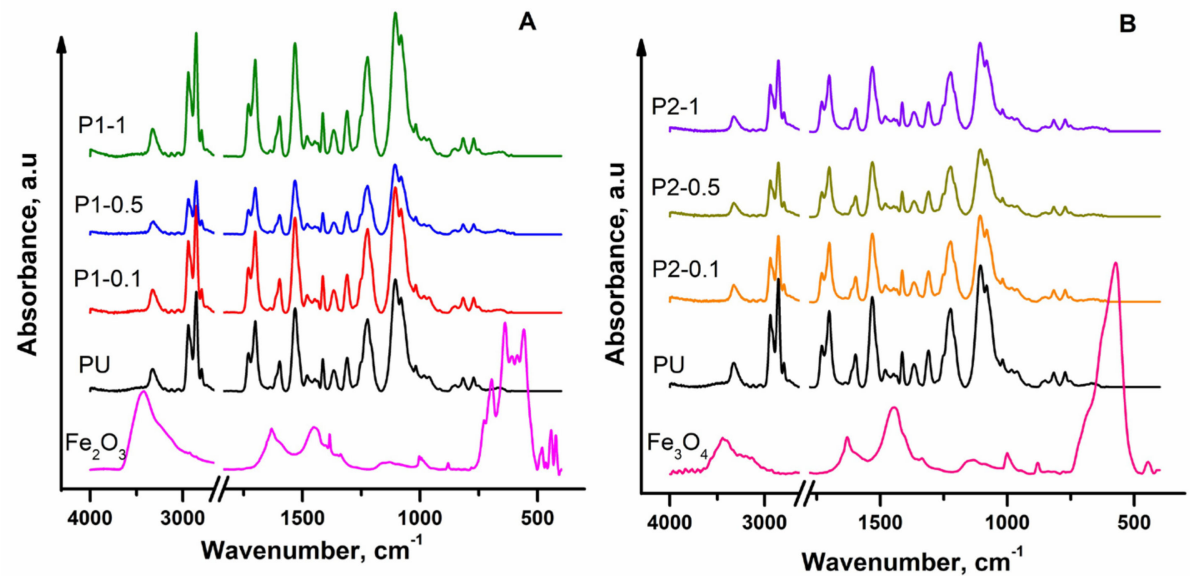

Figure 1. Comparison of ATR-FTIR spectra of: (A) pure $\mathrm{Fe}_{2} \mathrm{O}_{3}$ nanoparticles, pristine PU, and PU nanocomposites embedded with different amounts of $\mathrm{Fe}_{2} \mathrm{O}_{3}$ nanoparticles, and (B) pure $\mathrm{Fe}_{3} \mathrm{O}_{4}$ nanoparticles, pristine PU, and PU nanocomposites embedded with different amounts of $\mathrm{Fe}_{3} \mathrm{O}_{4}$ nanoparticles. 
In the $\mathrm{Fe}_{2} \mathrm{O}_{3}$ and $\mathrm{Fe}_{3} \mathrm{O}_{4}$ nanoparticles' spectra, the strong peaks at around 558 and $571 \mathrm{~cm}^{-1}$, respectively, were attributed to the vibrational frequency of the Fe-O bond [28]. In addition, the peaks observed at around $3423 \mathrm{~cm}^{-1}$ could be assigned to the $\mathrm{O}-\mathrm{H}$ stretching vibration of $\mathrm{H}_{2} \mathrm{O}$ due to the moisture absorption in iron oxide nanoparticles [42,43].

The FTIR spectrum of pristine PU showed typical bands related to the polyurethane structure: at $3326 \mathrm{~cm}^{-1}$, the absorption peak corresponding to the N-H stretching vibration could be seen; the bands at 2940 and $2854 \mathrm{~cm}^{-1}$ were assigned to the asymmetric and symmetric stretching vibration of the $\mathrm{C}-\mathrm{H}$ bond in $\mathrm{CH}_{2}$ groups; at 1731 and $1700 \mathrm{~cm}^{-1}$, the peaks corresponding to the free and bonded $\mathrm{C}=\mathrm{O}$ stretching of urethane could be observed; the peak at $1597 \mathrm{~cm}^{-1}$ was due to the $C=C$ stretching vibration of MDI; at $1532 \mathrm{~cm}^{-1}$, the $\mathrm{N}-\mathrm{H}$ bending band was visible; the peaks at 1412 and $1310 \mathrm{~cm}^{-1}$ were assigned to the $-\mathrm{CH}_{2}$ deformation vibration; between 1107 and $1031 \mathrm{~cm}^{-1}$, the bands corresponding to the $\mathrm{C}-\mathrm{O}-\mathrm{C}$ stretching vibration were observable $[13,31,37]$. These vibration bands confirmed the formation of a pure polyurethane structure.

The addition of different iron oxide nanoparticles into the polyurethane matrix did not change the FTIR spectra of composite membranes, as can be seen in the representative IR curves [20]. This means that the molecular interaction at the surfaces was not affected by the small amounts of nanoparticles, and no physical and chemical interactions between the polyurethane chains and nanoparticles were observed. Moreover, the signals characteristic of the polyurethane structure could cover or envelop the vibration of the iron oxide structure, due to the small amount of the nanoparticles embedded in the PU matrix.

\subsection{Mechanical Analysis}

Since we aimed to explore these composite matrices as custom-tailored materials for the preparation of some suitable devices to improve the image quality in MRI investigations, mechanical properties were considered an important issue. In general, these composite materials should have an improved elasticity and strength in order to enable the high performance of devices. Thus, the mechanical properties of pristine and PU nanocomposites were also investigated by tensile tests. The effects of the incorporation of different iron oxide nanoparticles as well as the amount of nanoparticle content on mechanical properties are illustrated in Figure 2. All the curves exhibited the same pattern, showing the characteristic of an elastomeric behaviour in three stages: an elastic deformation occurred firstly, then a stress hardening took place, and finally the curves stopped when the samples broke. As can be observed in Figure 2A, the strain percent increased with the nanoparticles' concentration and the tensile stress had a slight increase. For the samples P1-0.1 and P1-0.5 a decrease in the tensile strength was observed, meaning that these needed less stress to break, which could be attributed to different parameters such as the aggregation of the nanoparticles and the non-homogeneity of the samples [30,44]. A poorer dispersion of nanoparticles can result in more defects in the composites and, thus, can lead to poorer mechanical properties, as observed for these two samples. This behaviour was also observed in the elastic domain at low deformation of the graph (inset of the Figure 2A). 

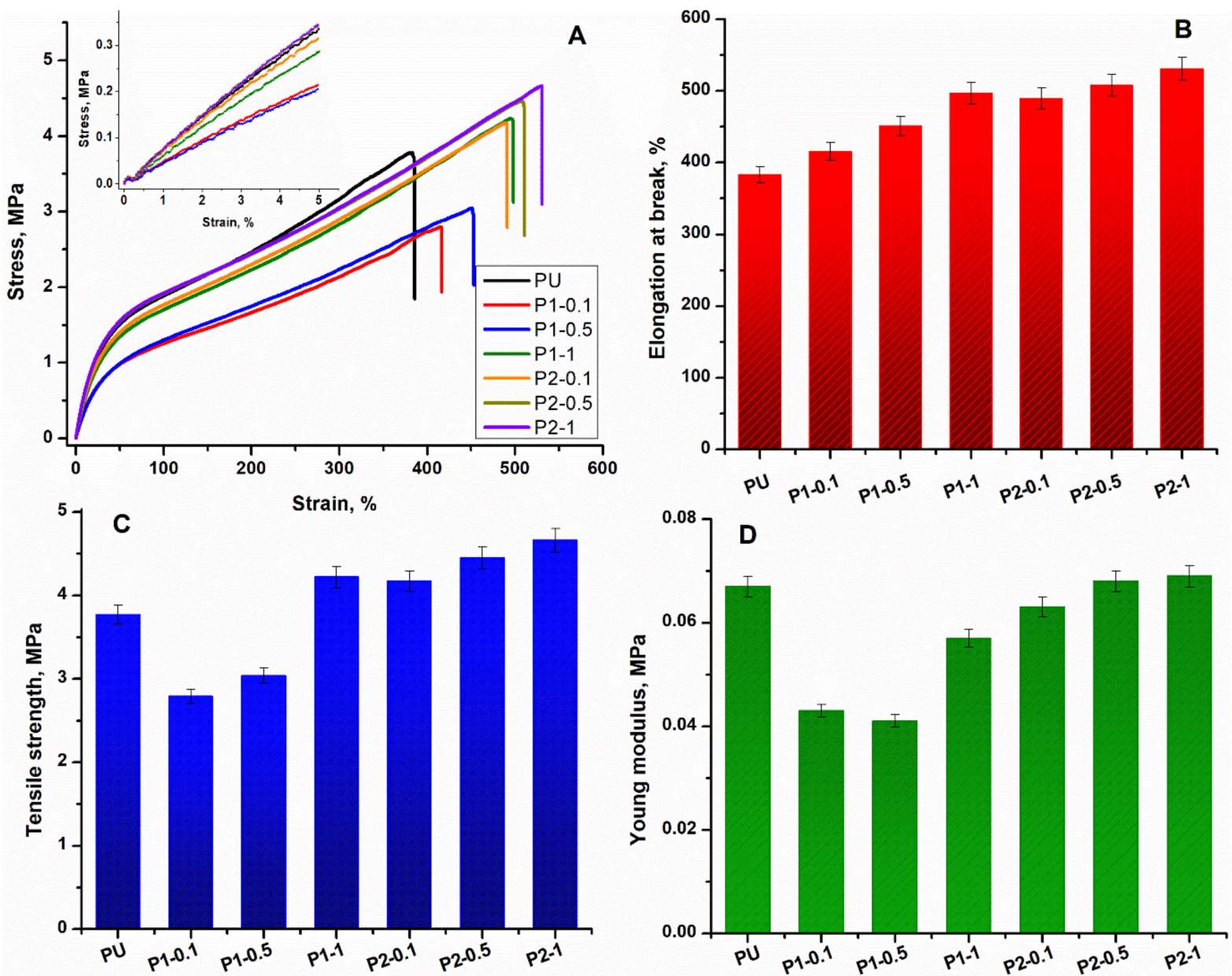

Figure 2. Mechanical analysis of the pristine and PU nanocomposite samples: (A) stress-strain curves. Inset: stress-strain curves in elastic region; (B) tensile strain; (C) tensile strength; and (D) Young's modulus.

The elongation at break increased from $380 \%$ at pristine $\mathrm{PU}$ up to $490 \%$ for the samples embedded with $1 \% \mathrm{Fe}_{2} \mathrm{O}_{3}$, and up to $530 \%$ for the samples with $1 \% \mathrm{Fe}_{3} \mathrm{O}_{4}$, respectively (Figure 2B). Thus, these results show that the elongation of the samples changed as a function of the iron oxides concentration.

Generally, the tensile strength also had a slight ascending trend with the increase in the nanoparticles' concentration (Figure 2C). The exceptions were the samples P1-0.1 (2.79 MPa) and P1-0.5 (3.04 MPa), which had lower tensile strength values compared with pristine PU (3.77 MPa). This behaviour could be due to the aggregation of the iron oxide nanoparticles, which created different stress concentration points [20]. As a result, the interactions between the agglomerated iron oxide nanoparticles and the PU matrix were not so strong as to overcome the applied stresses during the mechanical test [45]. Moreover, the addition of these iron oxide nanoparticles led to an increase in strength, especially for nanoparticles with high surface areas $\left(\mathrm{Fe}_{3} \mathrm{O}_{4}\right)$, as suggested by Fu et al. [46].

The Young's modulus is the ratio between the stress and strain of a material in the elastic domain at low deformation [46]. The results showed a slight decrease for the PU nanocomposite samples (0.057 MPa at P1-1 and 0.067 at P2-1) with respect to the values of the pristine PU matrix $(0.068 \mathrm{MPa})$, with the same exception for the samples P1-0.1 (0.043 MPa) and P1-0.5 (0.041 MPa), as was also previously observed for the tensile strength values (Figure 2D). This means that the samples with low modulus values could easily deform, were more elastic and presented a higher elongation until breaking. Regarding the influence of the nanoparticles' concentration, an increase in the modulus was observed with the increasing of the nanoparticle concentration. 


\subsection{Surface Morphology of the Samples}

The surface morphology and distribution of the nanoparticles are another important factor that can affect the quality and performance of the composite materials. In order to observe the microscale surface morphology of the pristine and nanocomposite PU samples, SEM images were obtained (Figure 3A). As can be seen, the surface of the pristine PU possessed an overall uniform surface morphology with small and large pores between 5 and $20 \mu \mathrm{m}$, which were interconnected. When $\mathrm{Fe}_{2} \mathrm{O}_{3}$ and $\mathrm{Fe}_{3} \mathrm{O}_{4}$ nanoparticles were added, the surface morphology was changed. As shown in the SEM images, diverse surface morphologies and possibly different surface-pertaining attributes arose from different nanoparticle concentrations. Thus, for the samples with low amounts of nanoparticles (P10.1 and P2-0.1), some pores could be observed and the nanoparticles were quite uniformly distributed. When the concentration increased (P1-1 and P2-1), the pores were collated and the nanoparticles were sometimes agglomerated (P1-1).
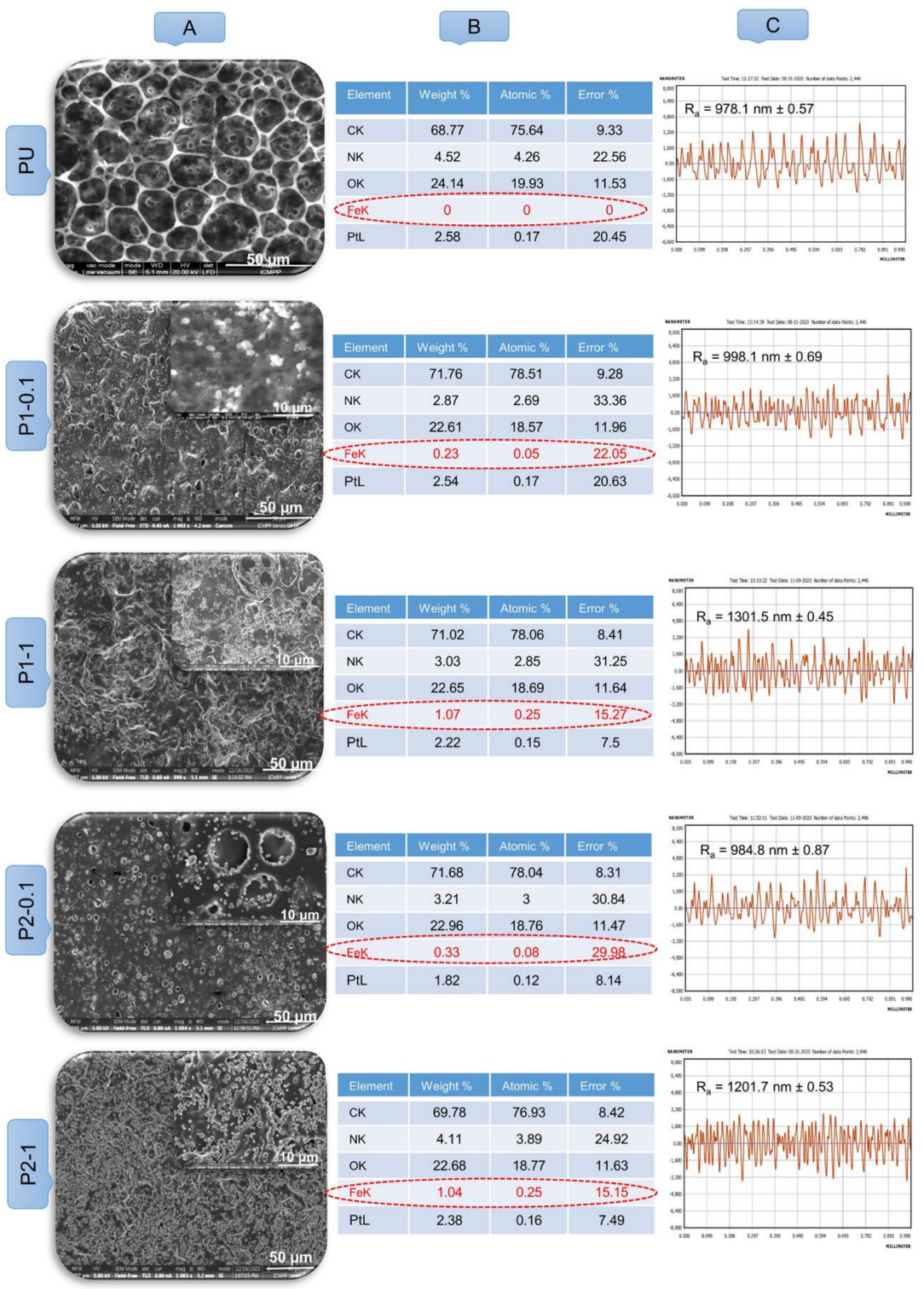

Figure 3. (A) Morphology from SEM images at 10 and $50 \mu \mathrm{m}$; (B) elemental composition; and (C) profilometry roughness of pristine and nanocomposite PU samples.

To study the presence and distribution of the hematite and magnetite nanoparticles on the surfaces, the elemental composition was examined under the same operational 
parameters and the results are shown in Figure 3B. It was found that increasing the nanoparticle content from 0.1 to $1 \%$ resulted in an increase in the amount of them at the surfaces, for example, from $0.23(\% w t)$ to $1.07(\% w t)$ for the samples with ferric oxide nanoparticles and from 0.33 to $1.04(\% \mathrm{wt})$ for the samples with magnetite nanoparticles.

\subsection{Profilometry Analysis}

Nanoscale topography is a complementary parameter of surface characterization, which affects the functional properties of the surfaces, including friction, wettability, biological response, etc. The surfaces of the prepared samples were studied by profilometry analysis and the corresponding images are shown in Figure $3 \mathrm{C}$. The average roughness $(\mathrm{Ra})$ values obtained from the analyses are also given in Figure $3 \mathrm{C}$ for each sample. By increasing the nanoparticle content from 0 to $0.1 \mathrm{wt} \%$, the Ra increased to its maximum value of 998.1 nm for sample P1-0.1 and $984.8 \mathrm{~nm}$ for P2-0.1, respectively, and further increased up to $1301.5 \mathrm{~nm}$ (P1-1) and $1201.7 \mathrm{~nm}$ (P2-1) for the samples with $1 \mathrm{wt} \%$ nanoparticles. It can also be observed that the nanoparticles' size had a small influence on the roughness. Thus, small nanoparticle sizes $\left(\mathrm{Fe}_{2} \mathrm{O}_{3}\right.$ of $50 \mathrm{~nm}$ size $)$ led to slightly rougher surfaces than those of the samples in which the magnetite nanoparticles $\left(\mathrm{Fe}_{3} \mathrm{O}_{4}\right.$ of $50-100 \mathrm{~nm}$ size) were included.

\subsection{Wettability and Surface Energy Parameters Study}

Surface wettability is a physical property that governs the interaction between the solid and liquid phases and is important in various biological systems and technological applications. Biomaterials, for example, must have hydrophobic surfaces in some applications such as those related to blood vessels $[47,48]$, and should be relatively hydrophilic in tissue engineering [49]. It is also one of the parameters that controls cell behaviour via protein adsorption at the material surface [50].

Investigation of the surface wettability of pristine PU and PU nanocomposites was performed by static contact angle (SCA) measurement between different polar and apolar testing liquid drops (W, EG, FA, dIM) and the surface of the samples. The contact angle values of pristine and nanocomposite $\mathrm{PU}$ samples, comprising different weight fractions of $\mathrm{Fe}_{2} \mathrm{O}_{3}$ and $\mathrm{Fe}_{3} \mathrm{O}_{4}$, are reported in Figure 4. Theoretically, a surface with an SCA lower than $90^{\circ}$ is hydrophilic and, in contrast, surfaces with static SCA greater than $90^{\circ}$ are hydrophobic. The results showed that the inorganic filler, i.e., iron oxide nanoparticles, influenced the PU surface in a different way. Thus, the incorporation of $\mathrm{Fe}_{2} \mathrm{O}_{3}$ nanoparticles increased the SCA of water, from $99.74^{\circ}$ for the pristine sample (PU) up to $108.96^{\circ}$ for the sample with $1 \%$ concentration (P1-1). This behaviour was due, on the one hand, to the increase in the roughness (Figure $3 \mathrm{C}$ ) of the surfaces, when air pockets were trapped in the rough cavities, leading to an increase in the surface hydrophobicity [51]. On the other hand, this increase in water SCA values was due to the increase in the $\mathrm{Fe}_{2} \mathrm{O}_{3}$ nanoparticles' concentration from 0.1 (P1-0.1) to $1 \%$ (P1-1) [52]. 

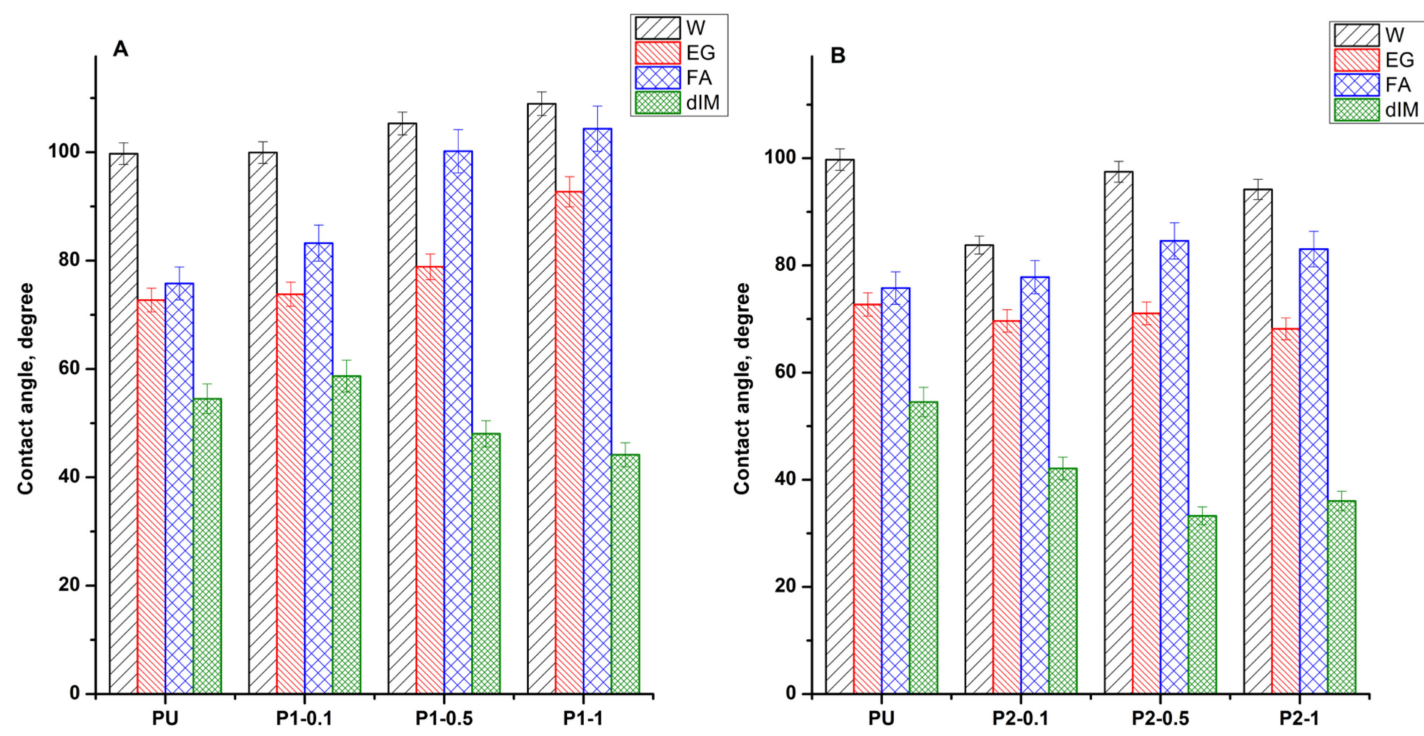

Figure 4. Static contact angle of pristine and PU nanocomposites: (A) with $\mathrm{Fe}_{2} \mathrm{O}_{3}$; (B) with $\mathrm{Fe}_{3} \mathrm{O}_{4}$.

On the contrary, the presence of the $\mathrm{Fe}_{3} \mathrm{O}_{4}$ nanoparticles led to a decrease in the water SCA until $83.80^{\circ}$ for the sample P2-0.1. This effect can be explained by the differences in the particles' sizes, which is also in agreement with the study performed by Kirchberg et al. [14]. Therefore, if we compare the SCA values obtained using different nanoparticle sizes at equal concentrations (e.g., $0.1 \%$ of $\mathrm{Fe}_{2} \mathrm{O}_{3}$ - sample P1-0.1; and of $\mathrm{Fe}_{3} \mathrm{O}_{4}$-sample $\mathrm{P2}-0.1)$, it can be observed that the incorporation of small nanoparticles $\left(\mathrm{Fe}_{2} \mathrm{O}_{3}\right.$ of $50 \mathrm{~nm}$ size) led to a rough surface (Figure $3 \mathrm{C}$ ) that corresponded to water repellence at the surface. When larger nanoparticles $\left(\mathrm{Fe}_{3} \mathrm{O}_{4}\right.$ of $50-100 \mathrm{~nm}$ size $)$ were dispersed in the PU matrix, a decrease in the water SCA was observed.

A similar trend was observed when the PU surfaces were in contact with other polar liquids such as ethylene glycol or formamide. In contrast, because of the high-dispersive component value, methylene iodide wet the surface easily and the SCA values were smaller.

The strength of binding between the phases could be assessed by determining the work of adhesion $\left(W_{a}\right)$, which was dependent on the surface tension of the tested liquid and its contact angle on the surfaces (Equation (3)) [35,38]. The calculated values of the $W_{a}$ are illustrated in Table 2.

Table 2. Work of adhesion and spreading coefficient values of pristine and PU nanocomposite samples.

\begin{tabular}{ccccccccc}
\hline $\begin{array}{c}\text { Sample } \\
\text { Code }\end{array}$ & W & EG & FA & dIM & W & EG & FA & dIM \\
\hline PU & 60.47 & 62.26 & 72.49 & 80.29 & -85.12 & -33.73 & -43.90 & -21.30 \\
P1-0.1 & 60.22 & 61.38 & 65.06 & 77.18 & -85.37 & -34.61 & -51.33 & -24.41 \\
P1-0.5 & 53.57 & 57.27 & 47.90 & 84.76 & -92.02 & -38.72 & -68.49 & -16.83 \\
P1-1 & 49.14 & 45.72 & 43.77 & 87.23 & -96.45 & -50.27 & -72.62 & -14.36 \\
P2-0.1 & 80.65 & 64.68 & 70.48 & 88.47 & -64.94 & -31.31 & -45.91 & -13.12 \\
P2-0.5 & 63.33 & 63.58 & 63.69 & 93.26 & -82.26 & -32.41 & -52.70 & -8.33 \\
P2-1 & 67.47 & 65.84 & 65.22 & 91.87 & -78.12 & -30.15 & -51.17 & -9.72 \\
\hline
\end{tabular}

The values of the $W_{a}$ measured with a nonpolar liquid (dIM) were higher than those measured with polar liquids, due to the strong interactions between the liquid and surface. Instead, when polar test liquids were used, the PU interface decreased the solid-liquid contact area due to the less wettability, and, therefore, decreased the $W_{a}$ [53].

In addition, the wettability of these PU samples was also described by the spreading coefficient $(S)$, a quantitative measure that represents the difference between the work of adhesion $\left(W_{a}\right)$ (solid-liquid interaction) and the work of cohesion $\left(W_{c}\right)$ (liquid-liquid 
interaction) (Equation (4)) [39]. $W_{c}$ was calculated based on this equation and was found to be 145.6, 96, 116.4, and $101.6 \mathrm{mN} / \mathrm{m}$, respectively, for $\mathrm{W}, \mathrm{EG}, \mathrm{FA}$, and dIM, respectively. The values of the $S$ parameters are also illustrated in Table 2 . This coefficient predicted the partially or totally wetting of surfaces by a liquid. As can be observed, the values were negative for all tested liquids, indicating that the liquids did not spread across the PU surfaces. This was due to the fact that the values of the $W_{c}$ were higher than those of $W_{a}$ and, thus, the liquid drops partially wet the solid surfaces.

The surface properties of the solids and, especially, the surface free energy (SFE) with its components, are the key to understanding the mechanism of surface-based phenomena, which are crucial in different applications including adhesion, coating, printing, etc. To determine the SFE of the PU samples, along with the polar and dispersive contributions, the values of the SCA measured with the test liquids were inserted into the evaluation method formulated by Owens, Wendt, Rabel, and Kaelble [35]. The SFE values with their polar and dispersive components of pristine and nanocomposite PU samples were calculated based on the Equations (1) and (2) and are illustrated in Table 3. The results indicated a significant difference between the dispersive $\left(\gamma_{s}^{d}\right)$ and the polar component $\left(\gamma_{s}^{p}\right)$, the dispersive contributions exceeding the polar components at all the studied samples, confirming the hydrophobic character of the surface samples. The polar component contribution to the overall SFE was close to zero due to the dominant arrangement of nonpolar species of the PU structure on the surfaces and due to the different Van der Waals interactions between the drop liquids and surfaces (Table 3). Thus, the existence of polar and non-polar groups on the surface directly influenced the wettability property. Generally, the solids that have lower surface free energies $\left(\gamma_{s}\right)$ exhibit higher values of water contact angles [35], as was also revealed in our results. The values of $\gamma_{s}$ decreased $\left(\sim 26-27 \mathrm{mN} / \mathrm{m}\right.$ at PU with $\mathrm{Fe}_{2} \mathrm{O}_{3}-$ P1 samples) or increased ( $31-34 \mathrm{mN} / \mathrm{m}$ at $\mathrm{PU}$ with $\mathrm{Fe}_{3} \mathrm{O}_{4}-\mathrm{P} 2$ samples) when compared with pristine PU $(30.55 \mathrm{mN} / \mathrm{m})$, depending on the experimental SCA values. The interfacial solid-liquid tension $\left(\gamma_{s l}\right)$ values increased with increasing contact angle values. These values can be high or low, depending on the attractive forces between the molecules of the liquid and solid [54].

Table 3. Surface tension parameters of pristine and PU nanocomposite samples calculated using the OWRK and Zisman methods.

\begin{tabular}{cccccc}
\hline $\begin{array}{c}\text { Sample } \\
\text { Code }\end{array}$ & $\begin{array}{c}\gamma^{d} \\
(\mathbf{m N} / \mathbf{m})\end{array}$ & $\begin{array}{c}\gamma_{s}^{p_{s}} \\
(\mathbf{m N} / \mathbf{m})\end{array}$ & $\begin{array}{c}\gamma_{s} \\
(\mathbf{m N} / \mathbf{m})\end{array}$ & $\begin{array}{c}\gamma_{s l} \\
(\mathbf{m N} / \mathbf{m})\end{array}$ & $\begin{array}{c}\gamma_{c} \\
(\mathbf{m N} / \mathbf{m})\end{array}$ \\
\hline PU & 30.25 & 0.30 & 30.55 & 38.24 & 26.43 \\
P1-0.1 & 26.58 & 0.49 & 27.08 & 37.24 & 22.58 \\
P1-0.5 & 27.50 & 0.02 & 27.52 & 43.03 & 25.61 \\
P1-1 & 26.66 & 0.25 & 26.91 & 35.27 & 19.22 \\
P2-0.1 & 29.09 & 2.60 & 31.69 & 14.78 & 19.85 \\
P2-0.5 & 35.06 & 0.04 & 35.11 & 35.13 & 32.15 \\
P2-1 & 33.87 & 0.32 & 34.19 & 31.35 & 31.49 \\
\hline
\end{tabular}

Zisman [35] showed that the cosines of the SCA formed by drops of liquids on a solid surface vary linearly with their surface tensions. The critical surface tension $\left(\gamma_{c}\right)$ can then be found by extrapolating the linear function to $\cos \theta=1$, and represents the maximum surface tension of a liquid that could completely wet the substrate [18]. The calculated values are given in Table 3. These values also depended on the experimental SCA values and presented the same increasing or decreasing trend as for the calculated SFE.

\subsection{Determination of Dynamic Vapours' Sorption and Diffusion Coefficients}

The sorption behaviour in polymers is a quite complex phenomena and the intensity depends upon the nature of the polymer (similar to polar/non-polar interactions) and the employed conditions. The water sorption capacity can provide important information about the prepared materials due to the fact that it is a critical factor in the determination of 
their stability, processing, storage, and applications. Moreover, the composite materials are exposed to water and humidity in their daily use and the attack of water and water vapour could lead to some modification of the product. This technique was used to determine the diffusion coefficients (D) of the samples using the methods developed by Crank [40] and Balik [55]. Thus, D was calculated from the plots of normalized mass change vs. time. The graphs are depicted in Figure 5, for both short and long time periods.
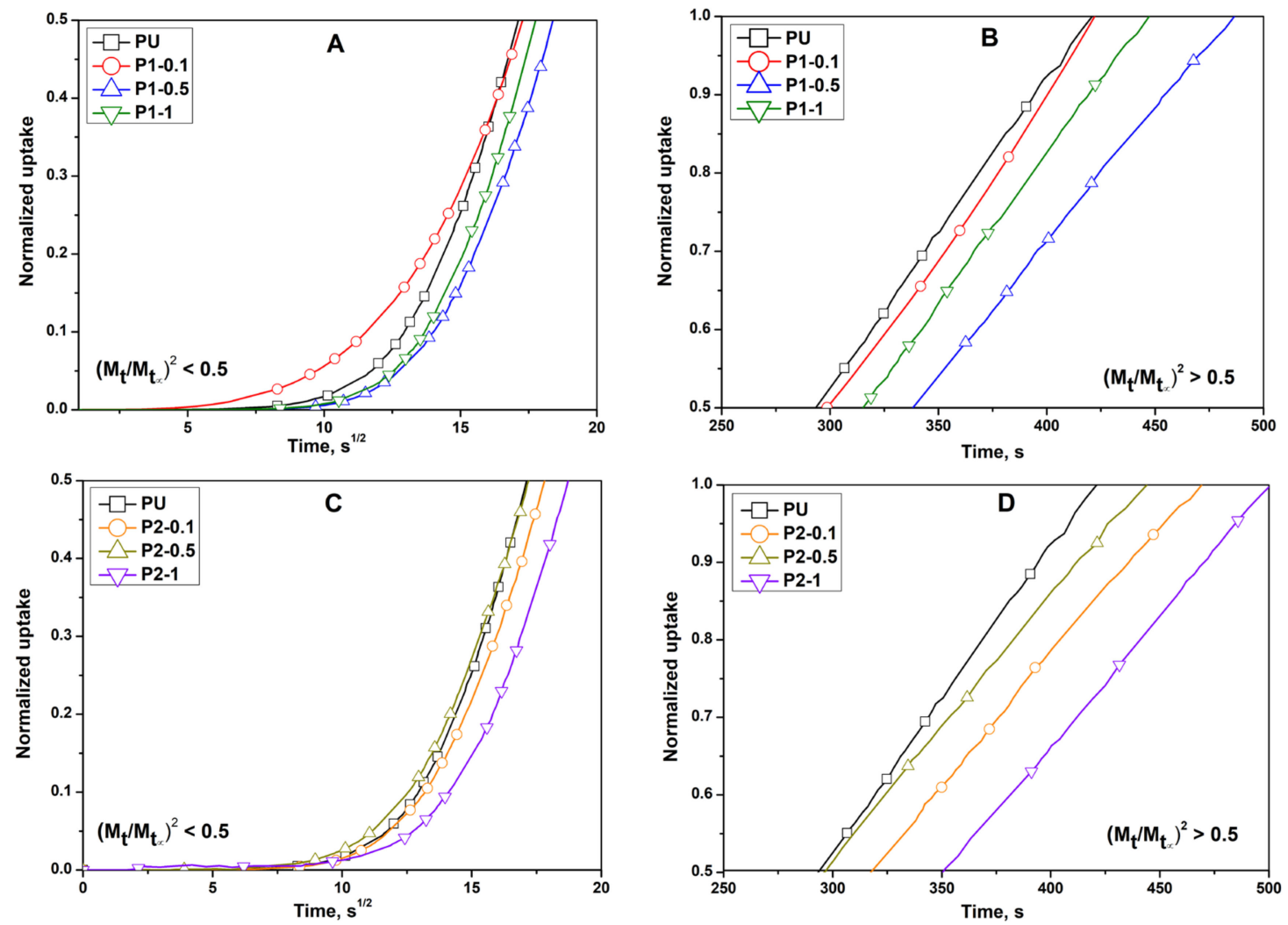

Figure 5. Normalized mass change as a function of time over $(\mathbf{A}, \mathbf{C})$ short time periods and $(\mathbf{B}, \mathbf{D})$ long time periods for the pristine and PU nanocomposite samples.

Therefore, over short time periods $\left(M_{t} / M_{\infty}<0.5\right)$, the initial kinetics of sorption into the polymer could be described by equation 5 and, for long time periods $\left(M_{t} / M_{\infty}>0.5\right)$, the kinetics could be described by equation 6 . The calculated values are illustrated in Table 4. Thus, over short time periods (Figure $5 \mathrm{~A}, \mathrm{C}$ ), the values of $D_{1}$ increased with the increasing of the nanoparticle content in the composite membranes, except when the concentration of nanoparticles was $1 \%$, in which cases these values were smaller than those of pristine PU for both P1-1 and P2-1. The increase could be partially explained by the polar nature of the iron oxide nanoparticles, which could have led to several other sites of interaction with water vapour molecules inside of the membranes, making diffusion easier. The observed deviation in the samples with high amounts of nanoparticles was possibly due to the non-homogenous distribution of the iron oxide nanoparticles in the composites (Figure 3A). Therefore, the void spaces around particles were not connected to each other in the same manner in each sample, leading to a decrease in $D_{1}$. 
Table 4. Diffusion coefficients determined from the experimental data of pristine and PU nanocomposite samples.

\begin{tabular}{|c|c|c|c|c|c|}
\hline $\begin{array}{c}\text { Sample } \\
\text { Code }\end{array}$ & $\begin{array}{c}D_{1} \times 10^{-7} \\
\left(\mathrm{~cm}^{2} / \mathrm{s}\right)\end{array}$ & $\begin{array}{c}D_{2} \times 10^{-7} \\
\left(\mathrm{~cm}^{2} / \mathrm{s}\right)\end{array}$ & $\begin{array}{c}K_{1} \times 10^{-3} \\
\left(\mathrm{~s}^{-1}\right)\end{array}$ & $\begin{array}{c}K_{2} \times 10^{-3} \\
\quad\left(\mathrm{~s}^{-1}\right)\end{array}$ & $\begin{array}{c}l \\
(\mathrm{~cm})\end{array}$ \\
\hline PU & 0.90 & 7.14 & 1.15 & -17.62 & 0.02 \\
\hline P1-0.1 & 1.04 & 5.05 & 1.48 & -12.46 & 0.02 \\
\hline P1-0.5 & 1.16 & 5.81 & 1.33 & -14.33 & 0.02 \\
\hline P1-1 & 0.76 & 6.42 & 0.97 & -15.84 & 0.02 \\
\hline P2-0.1 & 1.05 & 6.22 & 1.34 & -15.33 & 0.02 \\
\hline P2-0.5 & 1.13 & 5.59 & 1.44 & -13.78 & 0.02 \\
\hline P2-1 & 0.77 & 5.87 & 0.98 & -14.49 & 0.02 \\
\hline
\end{tabular}

$D_{1}$ is the diffusion coefficient calculated for short time periods $\left(M_{t} / M_{\infty}<0.5\right) ; D_{2}$ is the diffusion coefficient for long time periods $\left(M_{t} / M_{\infty}>0.5\right) ; K_{1}$ is the slope of linear regression between $\left(t-t_{R}\right)$ and $\left(M_{t} / M_{\infty}\right)^{2}$ for $\left(t-t_{R}\right) \geq 0$ and $\left(M_{t} / M_{\infty}\right)^{2}<0.2$ where $t_{R}$ is the time correlation for $M_{t} / M_{\infty}=0 ; K_{2}$ is slope of linear regression between $t$ and $\ln \left(1-M_{t} / M_{\infty}\right)$ for $-1.2>\ln >-3.0$.

Over long time periods (Figure $5 \mathrm{~B}, \mathrm{D}$ ), the values of $D_{2}$ were much higher than $D_{1}$ mainly due to the fact that the structures had enough time to expand, leading to an increase in the diffusion process. The diffusion decreased with the increasing of the nanoparticle content in the composite membranes, with the same deviation being maintained for the samples with high amounts of nanoparticles that were observed over short time periods. This behaviour could be attributed to the possible formation of some three-dimensional coordination complexes between iron oxides and polyurethane structures, leading to some crosslinking structures [56]. These would have prevented the rearrangement of the macromolecular chains during water vapour ingression and reduced the free volume in the composite, thereby causing resistance to the penetrants, resulting in a decrease in the diffusion process.

\subsection{Dielectric Properties}

The dielectric characteristics of polymer composites doped with iron oxide nanoparticles are of interest in relation to the construction of certain devices with applications related to biomedical engineering, microelectronics, nanotechnologies, etc [57-60]. Thus, the influence of different iron oxide nanoparticle contents on the dielectric behaviour of pure and PU nanocomposites was measured by dielectric spectrometry. According to the destination of the composite materials, a higher interfacial and dielectric polarisation was needed. When exposed to an electric field, the dielectric constant of the material, the so called permittivity $\left(\varepsilon^{\prime}\right)$, characterized the polarisation phenomena. The permittivity evolution, as a function of frequency, for pure and PU nanocomposites is shown in Figure 6. The permittivity values for the PU nanocomposites with $\mathrm{Fe}_{2} \mathrm{O}_{3}$ (Figure 6A) and for the $\mathrm{PU}$ nanocomposites with $\mathrm{Fe}_{3} \mathrm{O}_{4}$ (Figure 6D) suggested a small dependence on frequency in the range of $10^{1}-10^{6} \mathrm{~Hz}$. However, it should be noted that the values for P1-0.5 and P2-0.5 were very high, and quantities of iron oxide nanoparticles amounting to more or less than $0.5 \%$ tended to lower the interfacial polarisation and diminish the dielectric characteristics. 

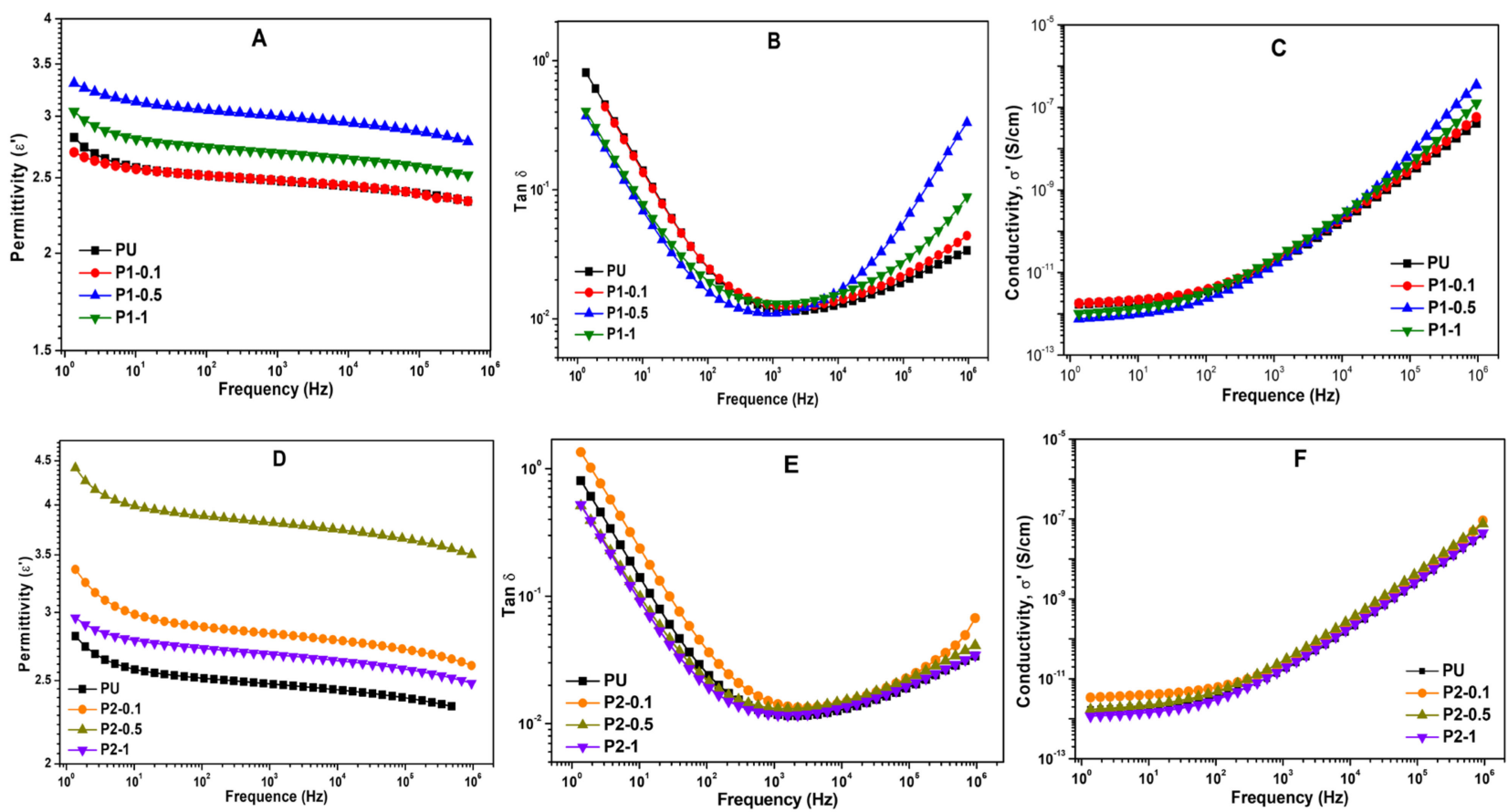

Figure 6. Variation of permittivity $\left(\varepsilon^{\prime}\right)(\mathbf{A}, \mathbf{D})$, dissipation factor $(\tan \delta)(\mathbf{B}, \mathbf{E})$, and conductivity $\left(\sigma^{\prime}\right)(\mathbf{C}, \mathbf{F})$ with frequency of pristine and PU nanocomposites.

The conductivity $\left(\sigma^{\prime}\right)$ of pure and PU composites (Figure 6C,F) increased slowly at low frequencies $\left(10^{0}-10^{2} \mathrm{~Hz}\right)$; however, the increase was more accentuated up to frequencies of $10^{6} \mathrm{~Hz}$. It was observed that the PU composites' conductivity curves, over the entire frequency range $\left(10^{0}-10^{6} \mathrm{~Hz}\right)$, were close to the conductivity of the pure PU curve. The presence of $\mathrm{Fe}_{2} \mathrm{O}_{3}$ and $\mathrm{Fe}_{3} \mathrm{O}_{4}$ nanoparticles introduced charge carriers into the PU matrix, and the relocation of the charge on the polymer chain helped to increase the conductivity, especially in the high frequency area, where the nano-dimension of the particles played a more important role.

The electrical energy stored by the material was characterized by the variation of $\tan \delta$ (Figure 6B,E). The values of $\tan \delta$ at lower frequencies were related to an important interfacial polarisation phenomenon. The slight increase in $\tan \delta$ at higher frequencies was explained by dielectric polarisation combined with an increase in conductivity. The samples with $0.5 \% \mathrm{Fe}_{2} \mathrm{O}_{3}$ (P1-0.5) and $\mathrm{Fe}_{3} \mathrm{O}_{4}$ (P2-0.5) showed good behaviour in terms of the values and evolution of $\tan \delta$, but they did not reach the percolation point.

Generally, for a material that is intended to be used for MRI applications, both a higher dielectric constant and a higher $\tan \delta$ value are required. We anticipate that by processing polymer composite membranes with ferromagnetic nanoparticles that are pre-oriented in the electric field, it is possible to obtain a higher and longer-lasting remnant polarization. From a technological point of view, when a pre-orientation of the electric charged nanoparticles takes place, this membrane must be kept under a pre-defined electric field; afterwards, the structure must be "frozen" in that position by increasing the temperature and evaporation of the solvent [61]. Thus, in order to obtain excellent dielectric properties, the nanoparticles' contents must be chosen very carefully in terms of their type, dimensions, and percentages. It is also important to achieve a pre-orientation of the nanoparticles with the use of specialized technology under a pre-defined electromagnetic field.

\subsection{Magnetic Properties}

In addition to their aforementioned properties, these composites could be used to improve the quality of MRI devices in biomedical applications. In this regard, the magnetic properties of the pristine and nanocomposite PU samples were studied in order to evaluate 
the influence of the content of iron nanoparticles on the well-known magnetic behaviour of iron. Figure 7 discloses the hysteresis loops of pristine and PU nanocomposite samples registered at room temperature. The pristine PU did not show magnetic properties due to the absence of magnetic particles in the matrix. The magnetization curves of the PU nanocomposites revealed a typical S-shaped superparamagnetic behaviour with negligible magnetic coercivity and remanence, i.e., the hysteresis loops exhibited a very low remanence effect at a low applied magnetic field (inset of Figure 7) [22]. The saturation magnetization of the PU nanocomposites was quite dependent on the content of iron oxide nanoparticles. Thus, the samples with low contents of iron oxide nanoparticles (P1-0.1 and P2-0.1) displayed a low saturation magnetization of 0.056 and $0.067 \mathrm{emu} / \mathrm{g}$, respectively. As expected, the saturation magnetization values gradually increased with the increasing of the loading of the iron nanoparticles, until values of 0.583 and $0.728 \mathrm{emu} / \mathrm{g}$ were reached for P1-1 and P2-1, respectively. However, the smaller saturation magnetization values of nanocomposites, as compared with those of the pure nanoparticles, were due to the low iron oxide content in the PU matrix ( $\max 1 \mathrm{wt} . \%$ ), the smaller nanoparticle sizes $(<50-100 \mathrm{~nm})$, and also to the surface coating of the iron oxide nanoparticles by the polymer chains $[44,62,63]$. The saturation magnetization was reached at a field of approximately 2000 Oe [64].
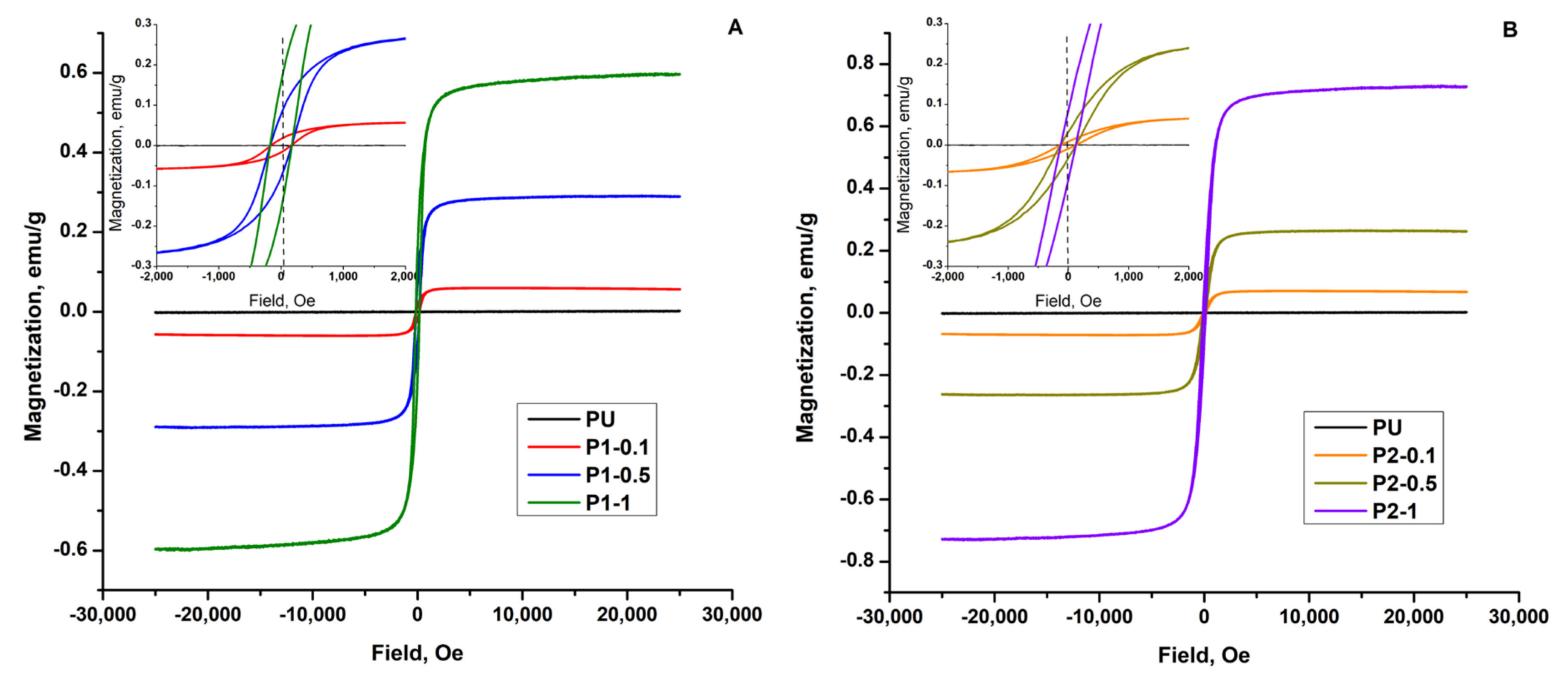

Figure 7. Magnetic hysteresis loops of pristine and PU nanocomposites at room temperature: (A) with $\mathrm{Fe}_{2} \mathrm{O}_{3} ;(\mathbf{B})$ with $\mathrm{Fe}_{3} \mathrm{O}_{4}$. The inset shows the hysteresis loops at low applied magnetic fields.

\subsection{Cytotoxicity Screenings and In Vitro Evaluation of Biocompatibility}

The cytotoxic effects of pristine and PU nanocomposite samples were evaluated by measuring the metabolic activity of epithelial cells using an MTT assay. Generally, cytotoxicity can be established on the basis of cell viability comparative to controls. Thus, activity levels of less than $30 \%$ are considered as representing severe cytotoxicity, values of between 30 and $60 \%$ denote moderate cytotoxicity, activity of between 60 and $90 \%$ indicates slight cytotoxicity, and for values greater than $90 \%$, it is assumed that a material is not cytotoxic $[65,66]$. Figure 8 shows the results of MTT assay for pristine and PU nanocomposite samples after 48 and 72 days of contact with epithelial cells. Compared to the control, the PU nanocomposite samples (P1-0.1, P1-0.5, P1-1, P2-0.1, P2-0.5, P2-1) maintained their cell viability at values in the range of $80-90 \%$ and it always remained higher than the viability recorded for pristine PU after $72 \mathrm{~h}$. There was a decrease in the cell viability ( $83 \%$ ) after $72 \mathrm{~h}$ of cell culture for the pristine samples (PU) compared to control, which can be considered as indicating very slight to no cytotoxicity. 


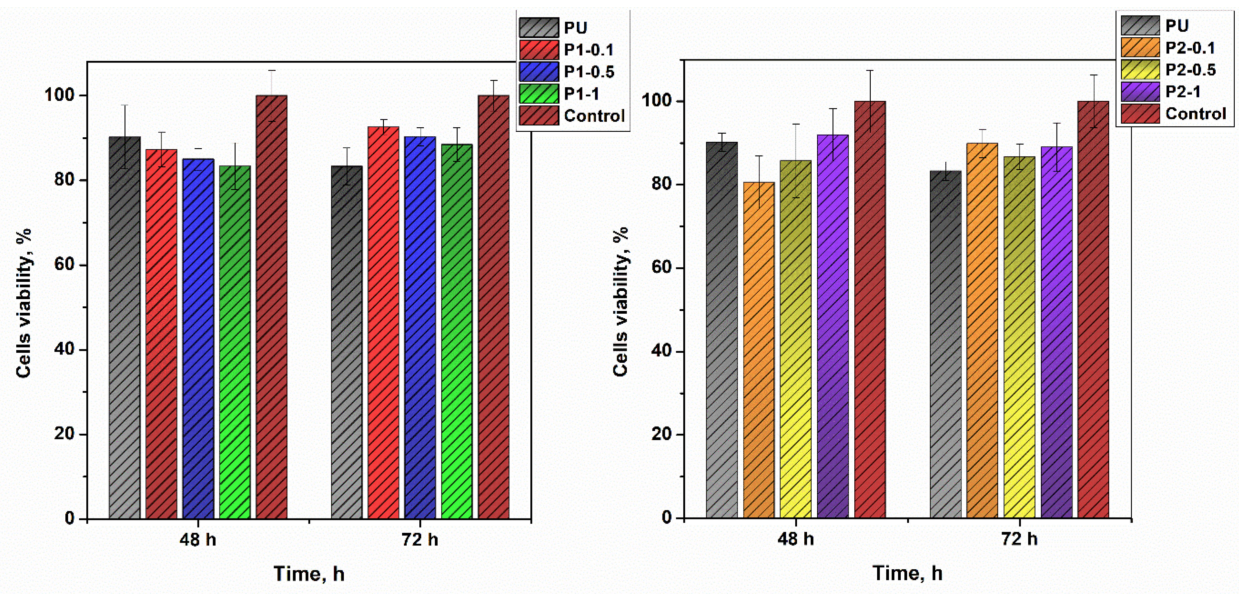

Figure 8. MTT assay showing the viability of epithelial cells in the presence of the pristine and PU nanocomposite samples at 48 and $72 \mathrm{~h}$.

The biocompatibility of pristine and PU nanocomposites was also investigated by means of a morphological evaluation of the epithelial cells after direct contact with the samples (Figures 9 and 10). Thus, when compared with the control, no differences were observed on the cell morphology. All the analysed nanocomposite films contained epithelial cells with a typical MCF 7-cell-line shape. After $72 \mathrm{~h}$ of culture, the cells grew in monolayers, with a very small difference in the density between the growth control and the analysed films. The cells were evenly distributed in the culture, including the areas containing the films that appeared as darker fields in the images. P1-0.1 and P2-0.1 had the best biocompatibility properties, maintaining cell viability at almost 93 and $90 \%$, respectively, after $72 \mathrm{~h}$ of cell incubation (Figure 8). Thus, the lower the iron concentration in PU nanocomposite samples, the better the non-toxicity properties. Similar behaviour was confirmed by other authors in a previous study [20], where the optimal concentration of $\mathrm{Fe}_{2} \mathrm{O}_{3}$ nanoparticles was found to be $0.1 \%$. It is known that the addition of iron nanoparticles into the polyurethane matrix improves the connectivity of the cells through their receptors because the iron nanoparticles have good conductivity properties [20]. Therefore, the obtained results indicated that the PU nanocomposite samples had good cytocompatibility and could be used in the chosen biomedical applications.
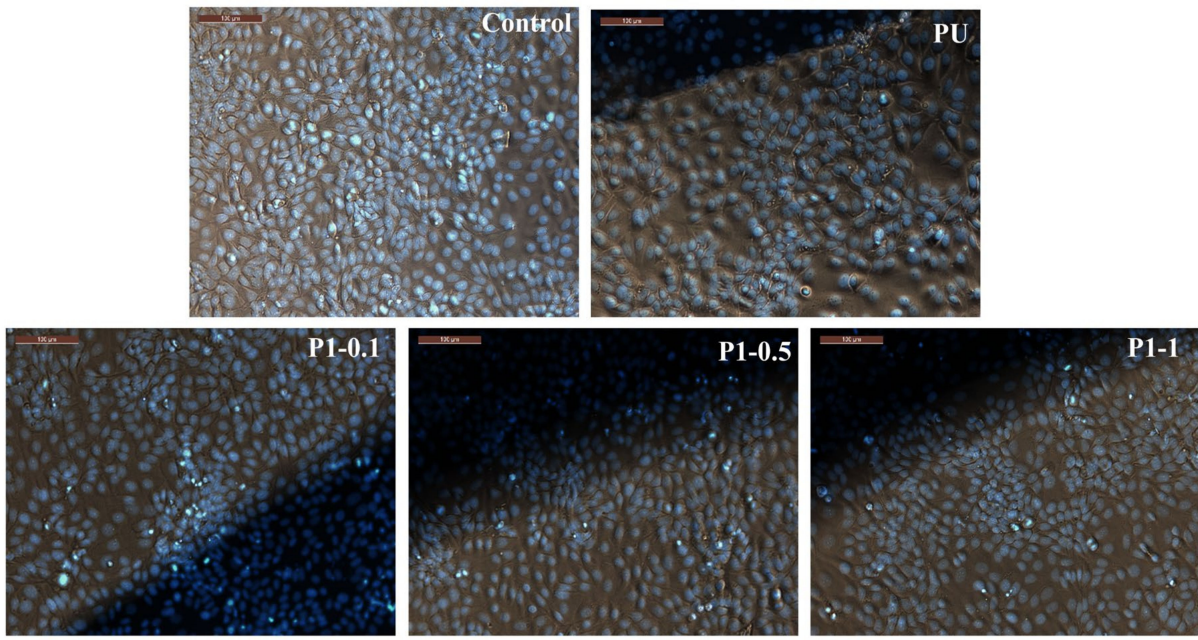

Figure 9. Morphological evaluation of epithelial cells after $72 \mathrm{~h}$ direct contact with the pristine and PU composites with different amounts of $\mathrm{Fe}_{2} \mathrm{O}_{3}$. 

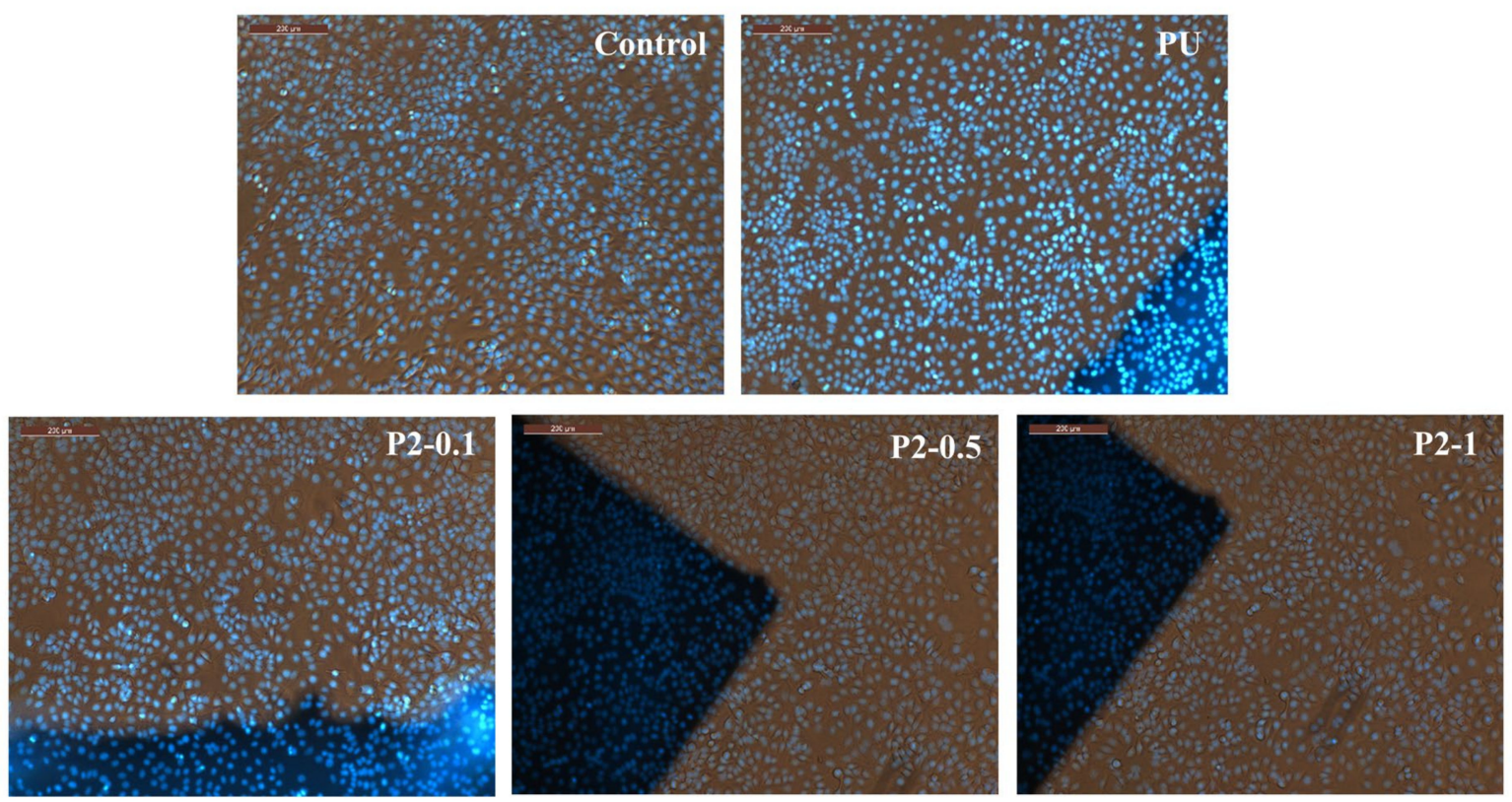

Figure 10. Morphological evaluation of epithelial cells after $72 \mathrm{~h}$ direct contact with the pristine and PU composites with different amounts of $\mathrm{Fe}_{3} \mathrm{O}_{4}$.

\section{Conclusions}

In the present research work, magnetic nanocomposites with poly(ether-urethane) used as their matrices and two types of iron oxide nanoparticle $\left(\mathrm{Fe}_{2} \mathrm{O}_{3}\right.$ and $\left.\mathrm{Fe}_{3} \mathrm{O}_{4}\right)$ as their nano-sized fillers were prepared and characterized. The nanocomposite PU membranes were prepared via solution casting by embedding different weight percentages $(0.1 ; 0.5$; $1 \%$ ) of both $\mathrm{Fe}_{2} \mathrm{O}_{3}$ and $\mathrm{Fe}_{3} \mathrm{O}_{4}$ nanoparticles into PU matrices (30 wt.\% in DMF) through blending. The effects of the amounts of nanoparticles on the various properties of the prepared PU nanocomposite membranes were investigated and compared with the results obtained for pristine PU. Thus, the chemical composition and molecular structure of the pure and PU nanocomposites were examined using FTIR-ATR analysis. The molecular interaction at the surfaces was not affected by the small amounts of nanoparticles and no physical or chemical interactions between the polyurethane chains and nanoparticles were observed. This was mainly due to the fact that the polyurethane structure could cover or envelop the vibration of the iron oxide structure. Mechanical analysis showed that the PU nanocomposites presented an elastomeric behaviour, with the elongation at break increasing from $380 \%$ for pure PU up to $490 \%$ for P1-1, and reaching $530 \%$ for P2-1. The Young's modulus showed a slight decrease for the PU nanocomposites $(0.057$ MPa for P1-1 and 0.067 for P2-1) with respect to the values of the pure PU matrix (0.068 $\mathrm{MPa}$ ), The introduction of different iron oxide nanoparticles afforded better mechanical properties of the PU nanocomposites as compared to those of the pristine PU. Different surface morphologies were observed for the pure and nanocomposite PU membranes with interconnected pores (average between 5 and $20 \mu \mathrm{m}$ ) for pure PU, and a fairly uniform distribution of nanoparticles was observed for the samples with low amounts of iron oxide nanoparticles and collated pores, and the agglomeration of nanoparticles was sometimes observed at high nanoparticle contents. The wettability of the surfaces depended on the roughness and size of the iron oxide nanoparticles. Thus, the incorporation of $\mathrm{Fe}_{2} \mathrm{O}_{3}$ nanoparticles increased the SCA of water, from $99.74^{\circ}$ at pure PU up to $108.96^{\circ}$ for P1-1. On the contrary, the presence of $\mathrm{Fe}_{3} \mathrm{O}_{4}$ nanoparticles led to a decrease in the water SCA to $83.80^{\circ}$ for the P2-0.1 sample. Water vapour diffusion increased over short time periods because of the polar nature of the iron oxide nanoparticles, and it decreased over long time periods due to the formation of 3D-crosslinking coordination complexes between the iron oxides and polyurethane structures. As expected, the magnetic properties were 
significantly enhanced with higher amounts of iron oxide nanoparticle loading ( 0.583 and $0.728 \mathrm{emu} / \mathrm{g}$ for P1-1 and P2-1, respectively), when compared with pure PU. In addition, the investigation of the in vitro biocompatibility of the prepared PU nanocomposites showed that, with cell viability levels in the range of $80-90 \%$, these samples are good candidates for biomedical applications. Considering all the investigations, we can conclude that these PU nanocomposites could be used as matrices for the preparation of certain suitable devices, particularly to improve the quality of MRI investigations.

Author Contributions: Conceptualization, L.M.G. and S.V.; methodology, M.D. and F.D.; investigation, F.D., M.B.M., M.A. (Magdalena Aflori), M.A. (Mihaela Aradoaei) and R.C.C.; biological investigation, M.B. and M.S.; writing-original draft preparation, L.M.G. and S.V.; writing-review and editing, L.M.G. and S.V. All authors have read and agreed to the published version of the manuscript.

Funding: This research was funded by the European Regional Development Fund, Contract no. 86/8.09.2016, MySMIS 105689.

Institutional Review Board Statement: Not applicable.

Informed Consent Statement: Not applicable.

Data Availability Statement: The data presented in this study are available on request from the corresponding author.

Acknowledgments: The authors acknowledge the financial support of this research through the European Regional Development Fund, Project "Partnerships for knowledge transfer in the field of polymer materials used in biomedical engineering", ID P_40_443, Contract no. 86/8.09.2016, MYSMIS 105689, co-financed by the European Regional Development Fund via the Competitiveness Operational Programme 2014-2020, Axis 1 Research, Technological Development and Innovation in support of economic competitiveness and business development, Action 1.2.3 Knowledge Transfer Partnerships.

Conflicts of Interest: The authors declare no conflict of interest.

\section{References}

1. Wu, M.; Shu, J. Multimodal molecular imaging: Current status and future directions. Contrast Media Mol. Imaging 2018, 2018, 7890241. [CrossRef]

2. Ahmad Saad, F.F. Molecular imaging. In Selected Topics on Computed Tomography; InTech: Oxford, UK, 2013; Volume 30, pp. 326-332.

3. Sun, C.; Lee, J.S.H.; Zhang, M. Magnetic nanoparticles in MR imaging and drug delivery. Adv. Drug Deliv. Rev. 2008, 60, 1252-1265. [CrossRef]

4. $\mathrm{Hu}, \mathrm{H}$. Recent advances of bioresponsive nano-sized contrast agents for ultra-high-field magnetic resonance imaging. Front. Chem. 2020, 8, 1-20. [CrossRef] [PubMed]

5. Smith, T.B.; Nayak, K.S. MRI artifacts and correction strategies. Imaging Med. 2010, 2, 445-457. [CrossRef]

6. Kudr, J.; Haddad, Y.; Richtera, L.; Heger, Z.; Cernak, M.; Adam, V.; Zitka, O. Magnetic nanoparticles: From design and synthesis to real world applications. Nanomaterials 2017, 7, 243. [CrossRef] [PubMed]

7. Khan, I.; Saeed, K.; Khan, I. Nanoparticles: Properties, applications and toxicities. Arab. J. Chem. 2019, 12, 908-931. [CrossRef]

8. Gradinaru, L.M.; Mandru, M.; Ciobanu, C.; Aflori, M. Opportunities and challenges in polymer-noble metal nanocomposites. In Intelligent Polymers for Nanomedicine and Biotechnologies; Taylor Francis Group: Abingdon, UK, 2017; ISBN 9781351977449.

9. Vlad, S.; Gradinaru, L.M.; Gradinaru, R.V.; Ciobanu, C. Recent developments in ZnO-polyurethane nanomaterials. In Intelligent Polymers for Nanomedicine and Biotechnologies; Taylor Francis Group: Abingdon, UK, 2017; ISBN 9781351977449.

10. Moghaddam, S.T.; Naimi-Jamal, M.R. Preparation of novel magnetic polyurethane flexible foam nanocomposites. Macromol. Symp. 2017, 375, 1600151. [CrossRef]

11. Mohammed, L.; Gomaa, H.G.; Ragab, D.; Zhu, J. Magnetic nanoparticles for environmental and biomedical applications: A review. Particuology 2017, 30,1-14. [CrossRef]

12. Diez-Pascual, A.M. Antibacterial nanocomposites based on thermosetting polymers derived from vegetable oils andmetal oxide nanoparticles. Polymers 2019, 11, 1790. [CrossRef]

13. Suhasini, A.; Kumar, K.P.V.; Maiyalagan, T. Synthesis, thermal and magnetic behavior of iron oxide-polymer nanocomposites. Sci. Eng. Compos. Mater. 2018, 25, 189-195. [CrossRef]

14. Kirchberg, S.; Abdin, Y.; Ziegmann, G. Influence of particle shape and size on the wetting behavior of soft magnetic micropowders. Powder Technol. 2011, 207, 311-317. [CrossRef] 
15. Achary, P.G.R.; Deo, S.S.; Munisha, B.; Choudhary, R.N.P.; Parida, S.K. Effect of temperature on electrical properties of PU/Fe (30\%) nanocomposite. J. Polym. Res. 2020, 27, 244. [CrossRef]

16. Vlad, S.; Filip, D.; Macocinschi, D.; Spiridon, I.; Nistor, A.; Gradinaru, L.M.; Musteata, V.E. New polyetherurethanes based on cellulose derivative for biomedical applications. Optoelectron. Adv. Mater. Rapid Commun. 2010, 4, 407-414.

17. Gradinaru, L.M.; Ciobanu, C.; Vlad, S.; Drobota, M.; Butnaru, M.; Saint-Pierre, G. Thermal behavior, surface energy analysis, and hemocompatibility of some polycarbonate urethanes for cardiac engineering. High Perform. Polym. 2015, 27, 637-645. [CrossRef]

18. Gradinaru, L.M.; Ciobanu, C.; Drobota, M.; Vlad, S. Poly(alkylene sebacate ether)urethane hydrogels for indomethacin delivery formulations. J. Polym. Res. 2017, 24, 99. [CrossRef]

19. Vlad, S.; Butnaru, M.; Filip, D.; Macocinschi, D.; Nistor, A.; Gradinaru, L.M.; Ciobanu, C. Polyetherurethane membranes modified with renewable resource as a potential candidate for biomedical applications. Dig. J. Nanomater. Biostruct. 2010, 5, 1089-1100.

20. Shahrousvand, M.; Hoseinian, M.S.; Ghollasi, M.; Karbalaeimahdi, A.; Salimi, A.; Tabar, F.A. Flexible magnetic polyurethane/Fe ${ }_{2} \mathrm{O}_{3}$ nanoparticles as organic-inorganic nanocomposites for biomedical applications: Properties and cell behavior. Mater. Sci. Eng. C 2017, 74, 556-567. [CrossRef]

21. Salimi, S.; Babra, T.S.; Dines, G.S.; Baskerville, S.W.; Hayes, W.; Greenland, B.W. Composite polyurethane adhesives that debond-on-demand by hysteresis heating in an oscillating magnetic field. Eur. Polym. J. 2019, 121, 109264. [CrossRef]

22. Yuwawech, K.; Wootthikanokkhan, J.; Tanpichai, S. Preparation and characterization of iron oxide decorated graphene nanoplatelets for use as barrier enhancing fillers in polyurethane based solar cell encapsulant. Mater. Today Proc. 2020, $23,703-711$. [CrossRef]

23. Morsi, S.M.M.; Mohamed, H.A.; Ghany, N.A.A. Development of advanced-functional polyurethane/red iron oxide composites as protective one coating systems for steel. Prog. Org. Coat. 2019, 136, 105236. [CrossRef]

24. Okoli, C.P.; Ofomaja, A.E. Development of sustainable magnetic polyurethane polymer nanocomposite for abatement of tetracycline antibiotics aqueous pollution: Response surface methodology and adsorption dynamics. J. Clean. Prod. 2019, 217, 42-55. [CrossRef]

25. Yu, T.; Halouane, F.; Mathias, D.; Barras, A.; Wang, Z.; Lv, A.; Lu, S.; Xu, W.; Meziane, D.; Tiercelin, N.; et al. Preparation of magnetic, superhydrophobic/superoleophilic polyurethane sponge: Separation of oil/water mixture and demulsification. Chem. Eng. J. 2020, 384, 123339. [CrossRef]

26. Hussein, F.B.; Abu-Zahra, N.H. Adsorption kinetics and evaluation study of iron oxide nanoparticles impregnated in polyurethane matrix for water filtration application. J. Miner. Mater. Charact. Eng. 2017, 5, 298-310. [CrossRef]

27. Dai, M.; Zhai, Y.; Wu, L.; Zhang, Y. Magnetic aligned $\mathrm{Fe}_{3} \mathrm{O}_{4}$-reduced graphene oxide/waterborne polyurethane composites with controllable structure for high microwaves absorption capacity. Carbon N. Y. 2019, 152, 661-670. [CrossRef]

28. Cheng, K.W.; Hsu, S.H. A facile method to prepare superparamagnetic iron oxide and hydrophobic drug-encapsulated biodegradable polyurethane nanoparticles. Int. J. Nanomed. 2017, 12, 1775-1789. [CrossRef]

29. Das, B.; Mandal, M.; Upadhyay, A.; Chattopadhyay, P.; Karak, N. Bio-based hyperbranched polyurethane $/ \mathrm{Fe}_{3} \mathrm{O}_{4}$ nanocomposites: Smart antibacterial biomaterials for biomedical devices and implants. Biomed. Mater. 2013, 8, 035003. [CrossRef]

30. Zhang, X.; Lu, X.; Wang, Z.; Wang, J.; Sun, Z. Biodegradable shape memory nanocomposites with thermal and magnetic field responsiveness. J. Biomater. Sci. Polym. Ed. 2013, 24, 1057-1070. [CrossRef]

31. Urban, M.; Strankowski, M. Shape memory polyurethane materials containing ferromagnetic iron oxide and graphene nanoplatelets. Materials 2017, 10, 1083. [CrossRef]

32. Stanciu, A.; Bulacovschi, V.; Lungu, M.; Vlad, S.; Balint, S.; Oprea, S. Mechanical behaviour of crosslinked poly(ester-siloxane) urethanes. Eur. Polym. J. 1999, 35, 2039-2044. [CrossRef]

33. Stanciu, A.; Bulacovschi, V.; Oprea, S.; Vlad, S. Thermal and mechanical behaviour of some new crosslinked poly(estersiloxane)urethanes. Polym. Degrad. Stab. 2001, 72, 551-558. [CrossRef]

34. Kozbial, A.; Li, Z.; Conaway, C.; McGinley, R.; Dhingra, S.; Vahdat, V.; Zhou, F.; Durso, B.; Liu, H.; Li, L. Study on the surface energy of graphene by contact angle measurements. Langmuir 2014, 30, 8598-8606. [CrossRef]

35. Erbil, Y. (Ed.) Surface Chemistry of Solid and Liquid Interfaces; Blackwell Publishing: Oxford, UK, 2006; ISBN 1-4051-1968-3.

36. Spiridon, I.; Anghel, N.; Dinu, M.V.; Vlad, S.; Bele, A.; Ciubotaru, B.I.; Verestiuc, L.; Pamfil, D. Development and performance of bioactive compounds-loaded cellulose/collagen/polyurethane materials. Polymers 2020, 12, 1191. [CrossRef]

37. Gradinaru, L.M.; Barbalata-Mandru, M.; Drobota, M.; Aflori, M.; Spiridon, M.; Pircalabioru, G.G.; Bleotu, C.; Butnaru, M.; Vlad, S. Preparation and evaluation of nanofibrous hydroxypropyl cellulose and $\beta$-cyclodextrin polyurethane composite mats. Nanomaterials 2020, 10, 754. [CrossRef] [PubMed]

38. Xue, M.; Ji, Y.; Ou, J.; Wang, F.; Li, C.; Lei, S.; Li, W. Surface wettability and strong adhesion of medical polyurethane elastomer porous films by microphase separation. AIP Adv. 2019, 9, 075309. [CrossRef]

39. Blanco, D.; Rivera, N.; Oulego, P.; Díaz, M.; González, R.; Battez, A.H. Novel fatty acid anion-based ionic liquids: Contact angle, surface tension, polarity fraction and spreading parameter. J. Mol. Liq. 2019, 288, 110995. [CrossRef]

40. Crank, J. The mathematics of diffusion. J. Am. Chem. Soc. 1975, 79, 1267-1268.

41. Stockert, J.C.; Blázquez-Castro, A.; Cañete, M.; Horobin, R.W.; Villanueva, Á. MTT assay for cell viability: Intracellular localization of the formazan product is in lipid droplets. Acta Histochem. 2012, 114, 785-796. [CrossRef]

42. Pooladian, B.; Alavi Nikje, M.M. Synthesis and characterization of poly(urethane-imide) nanocomposite films filled with iron oxide-silica and clay-silane-iron oxide nanoparticles. J. Plast. Film Sheeting 2018, 34, 196-218. [CrossRef] 
43. Song, C.; Wang, X.-X.; Zhang, J.; Nie, G.-D.; Luo, W.-L.; Fu, J.; Ramakrishna, S.; Long, Y.-Z. Electric field-assisted in situ precise deposition of electrospun $\gamma-\mathrm{Fe}_{2} \mathrm{O}_{3}$ /polyurethane nanofibers for magnetic hyperthermia. Nanoscale Res. Lett. 2018, $13,273$. [CrossRef]

44. Gao, Y.; Zhu, G.; Xu, S.; Ma, T.; Nie, J. Biodegradable magnetic-sensitive shape memory poly $(\varepsilon$-caprolactone $) / \mathrm{Fe}_{3} \mathrm{O}_{4}$ nanocomposites. J. Appl. Polym. Sci. 2018, 135, 45652. [CrossRef]

45. Ghosh, T.; Voit, B.; Karak, N. Polystyrene/thermoplastic polyurethane interpenetrating network-based nanocomposite with high-speed, thermo-responsive shape memory behavior. Polymer 2020, 200, 122575. [CrossRef]

46. Fu, S.Y.; Feng, X.Q.; Lauke, B.; Mai, Y.W. Effects of particle size, particle/matrix interface adhesion and particle loading on mechanical properties of particulate-polymer composites. Compos. Part B Eng. 2008, 39, 933-961. [CrossRef]

47. Zhao, X.; Courtney, J.M.; Qian, H. Blood interface biomaterials. In Biomaterials and Devices for the Circulatory System; Woodhead Publishing: Sawston, UK, 2010; pp. 24-53.

48. Erbulut, D.U.; Lazoglu, I. Biomaterials for improving the blood and tissue compatibility of total artificial hearts (TAH) and ventricular assist devices (VAD). In Biomaterials for Artificial Organs; Woodhead Publishing: Sawston, UK, 2011; pp. 207-235. ISBN 9781845696535 .

49. Balaji, A.; Jaganathan, S.K.; Ismail, A.F.; Rajasekar, R. Fabrication and hemocompatibility assessment of novel polyurethane-based bio-nanofibrous dressing loaded with honey and Carica papaya extract for the management of burn injuries. Int. J. Nanomed. 2016, 11, 4339-4355. [CrossRef]

50. Polini, A.; Yang, F. Physicochemical characterization of nanofiber composites. In Nanofiber Composites for Biomedical Applications; Elsevier: Amsterdam, The Netherlands, 2017; pp. 97-115. ISBN 9780081002087.

51. Tran, V.H.T.; Lee, B.K. Novel fabrication of a robust superhydrophobic PU@ZnO@Fe $\mathrm{O}_{4} @ S A$ sponge and its application in oil-water separations. Sci. Rep. 2017, 7, 17520. [CrossRef]

52. Manoudis, P.N.; Karapanagiotis, I. Modification of the wettability of polymer surfaces using nanoparticles. Prog. Org. Coatings 2014, 77, 331-338. [CrossRef]

53. Selvakumar, N.; Barshilia, H.C.; Rajam, K.S. Effect of substrate roughness on the apparent surface free energy of sputter deposited superhydrophobic polytetrafluoroethylene coatings: A comparison of experimental data with different theoretical models. $J$. Appl. Phys. 2010, 108, 732-741. [CrossRef]

54. Menzies, K.L.; Jones, L. The impact of contact angle on the biocompatibility of biomaterials. Optom. Vis. Sci. 2010, 87, 387-399. [CrossRef]

55. Balik, C.M. On the extraction of diffusion coefficients from gravimetric data for sorption of small molecules by polymer thin films. Macromolecules 1996, 29, 3025-3029. [CrossRef]

56. Ramesan, M.T. Effects of magnetite nanoparticles on morphology, processability, diffusion and transport behavior of ethylene vinyl acetate nanocomposites. Int. J. Plast. Technol. 2015, 19, 368-380. [CrossRef]

57. MacOcinschi, D.; Filip, D.; Vlad, S.; Cristea, M.; Musteata, V.; Ibanescu, S. Thermal, dynamic mechanical, and dielectric analyses of some polyurethane biocomposites. J. Biomater. Appl. 2012, 27, 119-129. [CrossRef] [PubMed]

58. Smaranda, I.; Nila, A.; Ganea, P.; Daescu, M.; Zgura, I.; Ciobanu, R.C.; Trandabat, A.; Baibarac, M. The influence of the ceramic nanoparticles on the thermoplastic polymers matrix: Their structural, optical, and conductive properties. Polymers 2021, 13, 2273. [CrossRef]

59. Iacob, M.; Tugui, C.; Tiron, V.; Bele, A.; Vlad, S.; Vasiliu, T.; Cazacu, M.; Vasiliu, A.L.; Racles, C. Iron oxide nanoparticles as dielectric and piezoelectric enhancers for silicone elastomers. Smart Mater. Struct. 2017, 26, 105046. [CrossRef]

60. Bele, A.; Cazacu, M.; Stiubianu, G.; Vlad, S. Silicone-barium titanate composites with increased electromechanical sensitivity. the effects of the filler morphology. RSC Adv. 2014, 4, 58522-58529. [CrossRef]

61. Wu, W.; Wu, Z.; Yu, T.; Jiang, C.; Kim, W.S. Recent progress on magnetic iron oxide nanoparticles: Synthesis, surface functional strategies and biomedical applications. Sci. Technol. Adv. Mater. 2015, 16, 23501. [CrossRef]

62. Kalita, H.; Karak, N. Hyperbranched polyurethane $/ \mathrm{Fe}_{3} \mathrm{O}_{4}$ thermosetting nanocomposites as shape memory materials. Polym. Bull. 2013, 70, 2953-2965. [CrossRef]

63. Salahuddin, N.; Rehab, A.; Abd-Elghany, S. In vitro thermo-triggered drug release from magnetic polyurethane-urea nanocomposite. J. Drug Deliv. Sci. Technol. 2020, 56, 101564. [CrossRef]

64. Li, L.; Zheng, S. Poly( $\varepsilon$-caprolactone)-grafted $\mathrm{Fe}_{3} \mathrm{O}_{4}$ nanoparticles: Preparation and superparamagnetic nanocomposites with epoxy thermosets. Ind. Eng. Chem. Res. 2015, 54, 171-180. [CrossRef]

65. Barrioni, B.R.; De Carvalho, S.M.; Oréfice, R.L.; De Oliveira, A.A.R.; Pereira, M.D.M. Synthesis and characterization of biodegradable polyurethane films based on HDI with hydrolyzable crosslinked bonds and a homogeneous structure for biomedical applications. Mater. Sci. Eng. C 2015, 52, 22-30. [CrossRef]

66. Amiri, B.; Ghollasi, M.; Shahrousvand, M.; Kamali, M.; Salimi, A. Osteoblast differentiation of mesenchymal stem cells on modified PES-PEG electrospun fibrous composites loaded with $\mathrm{Zn}_{2} \mathrm{SiO}_{4}$ bioceramic nanoparticles. Differentiation 2016, 92, 148-158. [CrossRef] 